Review

\title{
Development of Monolithic Column Materials for the Separation and Analysis of Glycans
}

\author{
Allan J. Alla and Keith J. Stine * \\ Department of Chemistry and Biochemistry, and Center for Nanoscience, \\ University of Missouri-Saint Louis, Saint Louis, MO 63121, USA \\ * Author to whom correspondence should be addressed; E-Mail: kstine@umsl.edu. \\ Academic Editor: Zuzana Zajickova
}

Received: 30 November 2014 / Accepted: 28 January 2015 / Published: 9 February 2015

\begin{abstract}
Monolithic column materials offer great advantages as chromatographic media in bioseparations and as solid-supports in biocatalysis. These single-piece porous materials have an interconnected ligament structure that limits the void volume inside the column, thus increasing the efficiency without sacrificing the permeability. The preparation of monolithic materials is easy, reproducible and has available a wide range of chemistries to utilize. Complex, heterogeneous and isobaric glycan structures require preparation methods that may include glycan release, separation and enrichment prior to a comprehensive and site-specific glycosylation analysis. Monolithic column materials aid that demand, as shown by the results reported by the research works presented in this review. These works include selective capture of glycans and glycoproteins via their interactions with lectins, boronic acids, hydrophobic, and hydrophilic/polar functional groups on monolith surfaces. It also includes immobilization of enzymes trypsin and PNGase F on monoliths to digest and deglycosylate glycoproteins and glycopeptides, respectively. The use of monolithic capillary columns for glycan separations through nano-liquid chromatography (nano-LC) and capillary electrochromatography (CEC) and coupling these columns to MS instruments to create multidimensional systems show the potential in the development of miniaturized, high-throughput and automated systems of glycan separation and analysis.
\end{abstract}

Keywords: glycan; glycoprotein; separation; monolith; column; lectin; boronate 


\section{Introduction}

Glycans are structures of monosaccharides or sugar building block units connected to each other in linear or branched arrangements. They are synonymously referred to as carbohydrates or as oligosaccharides. They exist either in free, unconjugated forms or covalently linked to proteins, peptides, lipids or saccharides to form glycoconjugates such as glycoproteins, glycopeptides, proteoglycans, peptidoglycans, glycolipids and lipopolysaccharides. The compositions, configurations, and linkages vary from one glycan to another making their structures complex and heterogeneous. As a consequence, glycans developed diverse biological functions that can be summed up into two main categories: (1) as specific recognition mediators, e.g., receptors to pathogens and cells, and (2) as biological process modulators, e.g., on-off switches of protein function [1]. Studying the structures and biological functions of glycans, whether as free glycans or in glycoconjugates is called glycomics. The current strategy in glycomics is the improvement of the existing preparative methods to obtain excellent structural characterization analysis. A specific approach is the development of materials used as stationary phases, matrices and capillaries of columns used in the separation, extraction, enrichment and release of glycans. Monolithic materials are now becoming good choices in designing columns due to their higher permeability, excellent convective mass transfer, ease of preparation and compatibility for integration with mass spectrometry (MS) instruments. A number of reviews have been written about monolithic materials and their uses in bioseparations [2-8]. In this review, we focus on the development of monolithic column materials used as solid supports for enzymes to release glycans, stationary phases for separation and enrichment of glycans, glycopeptides and glycoproteins and as sorbents for extraction of glycoproteins from biological samples. We focus on glycans of glycoproteins as influenced by the growing and recent literature.

\section{Glycans, Glycosylation and Glycoproteins}

Peptides undergo post-translational modifications (PTMs) in protein synthesis. PTMs include phosphorylation, methylation, acetylation and glycosylation. Glycosylation is the most prevalent PTM in proteins wherein glycans are covalently linked to an amino acid sequence through the action of a glycosyltransferase enzyme. Glycoproteins are products of glycosylation, and a majority of attached glycans are either N-linked or O-linked. Other known modes of glycosylation include C-mannosylation (first described for human RNase 2 [9]), O-fucosylation [10], phosphoglycosylation [11] and glypiation [12]. $\mathrm{N}$-linked glycosylation is more readily studied due to the availability of a selective method to release $\mathrm{N}$-glycans, namely use of the enzyme peptide N-glycosidase F (PNGase F) [13]. N-glycans can also be released by chemical means via hydrazinolysis [14]. N-linked glycans are linked to proteins through the $\mathrm{N}$ of asparagine (Asn), and have a consensus sequence of Asn-X-Ser/Thr where $\mathrm{X}$ is any amino acid except Pro. N-linked glycans have a common core oligosaccharide Man3GlcNAc2. O-linked glycosylation, on the other hand, occurs by the linkage to the $\mathrm{O}$ of Ser or Thr. Unlike $\mathrm{N}$-glycans, O-glycans do not have a conserved structural core, or a consensus sequence. O-glycans are typically released by $\beta$-elimination via treatment with mild base or borohydride [15]. The biological functions and structure of glycosylated proteins are influenced by the attached glycans and aberrant glycosylation has been shown to be correlated to certain mammalian diseases like cancers [16]. In glycomics, the main goal is to determine the biological functions of glycans. The prerequisites are accurate structural information and identification 
of sites of glycosylation. Monitoring the glycosylation site and structure of linked glycans in glycoproteins is important. Glycoproteins are now useful research tools in biomedical research due to their therapeutic response to drugs. An example is the presence of single nucleotide polymorphisms (SNP) in human P-glycoproteins that play an important role in drug delivery through their contribution to multidrug resistance. These membrane glycoproteins function as drug efflux pumps and are expressed by both tumor and normal cells [17]. In human P-glycoprotein, glycosylation can occur on Asn-91, Asn-94, or Asn-99 in the first extracellular loop resulting in as many as three unique glycans attached [18]. Over 50 SNPs have been identified for this protein, and can result in variation in polymorphism and glycosylation, as are sometimes associated with tumor progression. Expression of mutants of human P-glycoprotein including those lacking all three glycans showed that the non-glycosylated protein retained its function; however, removal of the glycans reduced the level of expression of the protein at the cell surface [19]. Glycoproteins are also currently used as biomarkers for the detection of certain diseases such as carcinoembryonic antigen (CEA) [20] and prostate specific antigen (PSA) [21].

\subsection{Complex and Heterogeneous Structure of Glycans}

The difficulty in analysis of glycans can be attributed to five reasons: (1) variable composition; (2) branching; (3) isomeric forms; (4) multiple glycosylation sites; and (5) presence of terminal units such as sialic acids [22]. These characteristics make the glycan structure complex and heterogeneous (Figure 1).

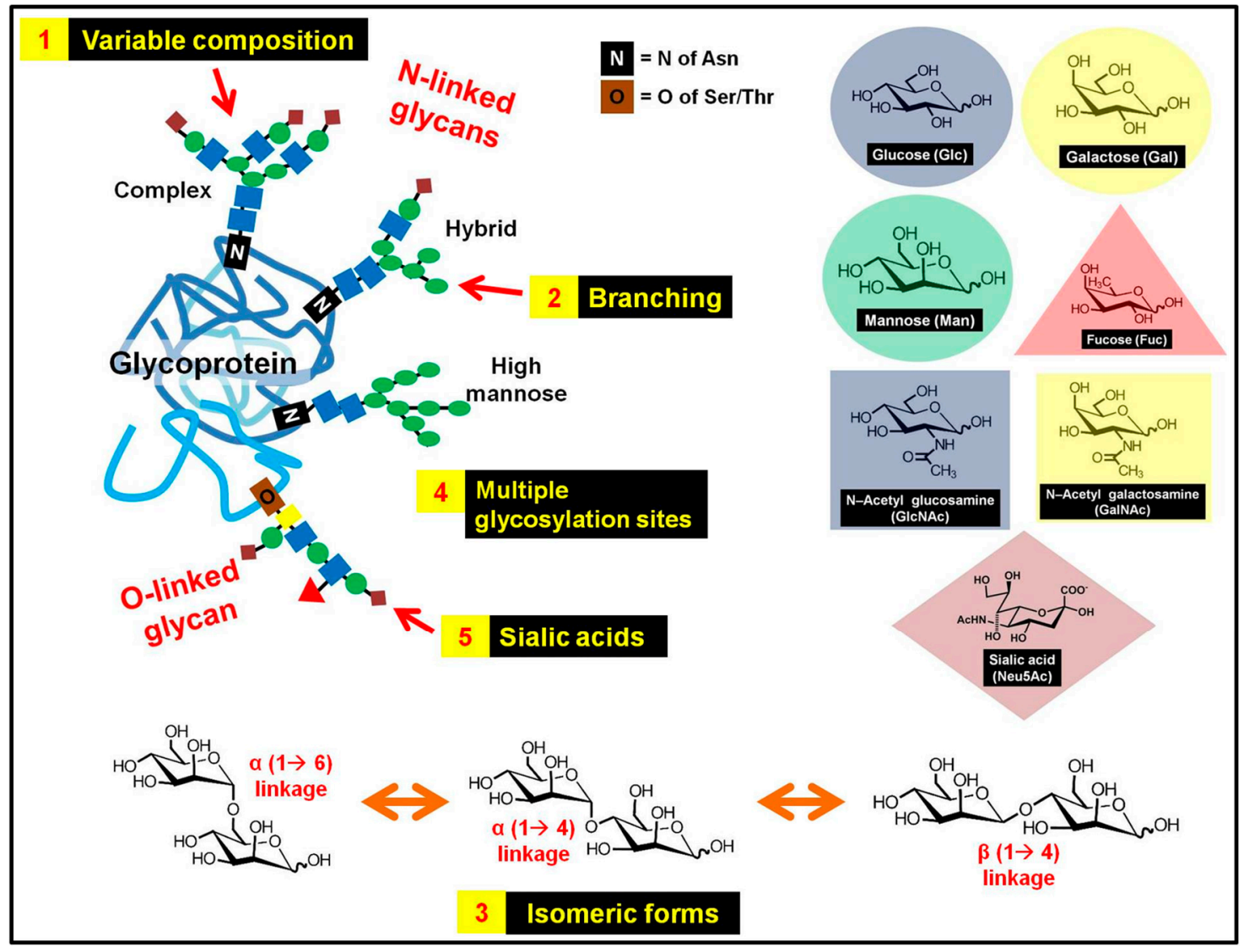

Figure 1. The challenges in separation and analysis of glycans: complex and heterogeneous structure of glycans due to variable monosaccharide composition, branching, isomeric forms, multiple glycosylation sites of glycoconjugates and presence of terminal sialic acids. 
Monosaccharide units such as mannose (Man), galactose (Gal), glucose (Glc), fucose (Fuc), $\mathrm{N}$-acetylglucosamine (GlcNAc) and N-acetylgalactosamine (GalNAc) build up glycans and their composition in glycans can be either homogeneous or heterogeneous. Unlike proteins, glycans do not have an organized and DNA template-driven synthesis. Glycans are synthesized by repetitive and overlapping reactions of different enzymes, sugar nucleotide transporters and other cellular machinery, therefore, branching may occur. Due to the chirality of the anomeric carbon atoms in the monosaccharide units, carbohydrate isomers ( $\alpha$ and $\beta$ ) exist. Isomers exist also due to the variety of possible linkages (e.g., $1 \rightarrow 2,1 \rightarrow 3,1 \rightarrow 4,1 \rightarrow 6$ ) between sugar units. These isomers, which have the same mass, will have the same mass-to-charge ratio $(\mathrm{m} / \mathrm{z})$ values in MS analysis, and therefore may limit the accuracy of the analysis. Glycosylation may occur at more than one amino acid sequence in a peptide. Therefore, different glycan structures can be linked to a specific amino acid residue of the same protein. Some glycoproteins show the same amino acid sequence but differ with respect to the number, location, or sequence of attached glycans. These are called "glycoforms". Therefore, one glycoform may have more heterogeneous attached glycans than the other and also attached glycans present on one glycoform may be absent on another. Glycans also undergo post-assembly modification and one of the most common is the addition of negatively charged sialic acids to terminal regions. Carboxylic acid-functional groups of sialic acids reduce the ionization efficiency of glycans in positive ion mode MS. Advanced strategies and comprehensive analysis have been reported such as three-dimensional mapping of carbohydrates [23] and some other techniques [24,25], but the search is still on for high-throughput and more effective and sensitive methods of glycan analysis.

\subsection{Approach in Glycomics}

The current approach in glycomics is the structural characterization of glycans and deglycosylated peptides that provide "marks" to locate the glycosylation sites. The two main challenges in glycomics are: (1) the complex and heterogeneous structure of glycans described above; and (2) the very low ratio of glycans and glycopeptides to other components in complex biological samples and glycan pools.

Glycans that have been reductively aminated with a chromophoric group and separated by HPLC methods can be detected by UV or fluorescence detection [26]. Because glycans lack a chromophore in their native state, derivatization of reduced glycans by chromophore or fluorophore labeling is usually necessary prior to UV and fluorescence detection [27]. Other methods of detecting underivatized glycans are indirect UV detection [28] and electrochemical detection [29]. High-throughput screening of glycans using lectin [30] and antibody [31,32] microarrays is also an option. Labeling of glycans also allows for visualization of glycoprotein bands in gel electrophoresis [33].

There are a number of approaches to the structural characterization of glycans and identification of glycosylation sites for glycan sequencing and linkage analysis. NMR spectroscopy is a powerful tool to characterize underivatized glycans that can provide three-dimensional structures that include information about stereochemistry, linkage sequence and position of glycans in glycopeptides [34]. Due to the low natural abundance of NMR active nuclei of glycans such as ${ }^{13} \mathrm{C}$ and ${ }^{1} \mathrm{H}$, acquiring adequate NMR spectra requires at least a microgram of sample for the case of seeking a full structural assignment of a trisaccharide [34]. Efforts to reduce the required amount of glycan for NMR analysis are under development [35]. NMR elucidation of glycan structure can be enhanced using computational methods [36] and $x$-ray crystallography together with molecular modeling [37]. 
However, the most widely used and developed technique for the structural characterization of glycans is mass spectrometry (MS) analysis coupled to preparative methods such as in liquid chromatography (LC-MS) [38-40]. Structural elucidation based on LC-MS data such as retention or migration times, mass-to-charge ratio $(\mathrm{m} / \mathrm{z})$ and fragmentation spectra can provide sequence, branching and linkage information [41]. In a concise way, MS analysis can be described as a series of steps of ionization, separation and detection. The MS data plot is shown as relative abundance of detected ions versus $\mathrm{m} / \mathrm{z}$.

Some of the modern detection methods used in MS instruments for glycomics include quadrupole ion trap, time of flight (TOF), oribitrap, magnetic sector, and Fourier transform ion cyclotron resonance (FT-ICR) $[42,43]$. Of these methods, the quadrupole ion trap has the disadvantage of lower mass accuracy $(\sim 50 \mathrm{ppm})$ than the others, of which FT-ICR and magnetic sector have the highest $\sim 1$ ppm mass accuracy. The orbitrap detection method has both high mass accuracy ( $\sim 2 \mathrm{ppm})$ and high sensitivity [44]. Ion trap methods allow for the ejection of all but one selected ion that can then be subjected to further fragmentation thus facilitating MS/MS experiments [45]. The mass range of quadrupole ion traps of up to about $m / z=4000$ is well suited for the peptides introduced by electrospray ionization (ESI) [46]. A higher $\mathrm{m} / \mathrm{z}$ limit of 6000 can be achieved using the orbitrap [44]. TOF, as used in matrix-assisted laser desorption ionization-time of flight (MALDI-TOF) can access very high $\mathrm{m} / z$ values of $~ 200,000$ [47]. TOF mass resolution is improved by incorporation of a reflectron [48]. Resolving power $(\mathrm{m} / \Delta \mathrm{m})$ is very high $\left(\sim 1 \times 10^{6}\right)$ for FT-ICR detection and enables distinguishing glycans permethylated with ${ }^{13} \mathrm{CH}_{3}$ from those permethylated with ${ }^{12} \mathrm{CH}_{3}$ [49]. In comparison, the resolving power for quadrupole ion trap is $\sim 1 \times 10^{4}$ with the other noted methods falling between these two limits [44]. Earlier linear ion trap or triple quadrupole analyzers will have much lower mass accuracy, somewhat lower $m / z$ range, and less resolving power [50] but may be suitable for less demanding applications. A limitation of linear ion traps, known as the "one-third rule" is the decreased stability of fragment ions with $\mathrm{m} / \mathrm{z}$ less than $30 \%$ of the $m / z$ value of the precursor ion selected by collision-induced dissociation during MS/MS [51,52].

Aside from the rapid developments in cell biology, the major contribution to the success of glycomics is the huge improvement in MS instruments. The sensitivity of MS was enhanced by using soft ionization techniques such as ESI [53] and MALDI [54]. Using these advanced ionization techniques, peptides can be detected at femtomolar concentration ranges while underivatized glycans need to be at picomolar levels to be detected [55]. These limits can be improved by some glycan derivatization techniques such as labeling with 2-aminobenzamide (2-AB) [56]. Permethylation or the conversion of $\mathrm{OH}$ groups of glycans to methyl ethers increases the stability of glycans by making them hydrophobic and able to withstand multiple rounds of MS analysis, i.e., tandem MS analysis [57]. Tandem MS (MS/MS or MS ${ }^{\mathrm{N}}$ ) analysis can be employed for proteins to further separate a peptide into fragments [58]. For glycans, tandem MS analysis can resolve structural isomers [59] and large number of variations in linkage and branching [60]. Collision induced dissociation (CID) is commonly used to fragment precursor ions for the next round of MS analysis [61]. Tandem MS can be enhanced by different analyzers, such as quadruple ion trap [62] and Fourier transform MS (FT-MS) [63]. Nano-ESI-MS improved the detection limits down to attomole level with use of ion-trap MS (IT-MS) with the direct infusion of a sample solution $[64,65]$. More developments in MS instruments utilized in glycan analysis are summarized in several reviews [66-70]. Though the benefits of glycan analysis in using MS instruments are overwhelming, there are still some limitations such as non-selective ionization and fragmentation of peptides and degradation of the samples during the sequence of excitation, trapping and detection. The loss of sialic acid residues that can occur in MALDI-TOF is an example [71]. 
The method of ${ }^{18} \mathrm{O}$ labeling was first introduced as a means of labeling peptides by the trypsincatalyzed exchange of two ${ }^{16} \mathrm{O}$ atoms for two ${ }^{18} \mathrm{O}$ atoms in the $\mathrm{C}$-terminal carboxyl group of a peptide produced by action of trypsin which yields a mass increase of $+4 \mathrm{Da}$ [72]. Deglycosylation by PNGase $\mathrm{F}$ in ${ }^{18} \mathrm{O}$-enriched water aids in the identification of N-linked glycosylation sites of glycoproteins by MS [73]. The action of PNGase F both cleaves off the glycan and converts the asparagine (Asn) to aspartic acid (Asp) resulting in a mass shift of $0.984 \mathrm{Da}$ for the peptide. However, non-enzymatic deamidation can occur at an Asn that has no glycan potentially resulting in a false positive identification of a glycosylation site $[74,75]$. Such chemical deamidation may also occur at Gln sites. Enzymatic deglycosylation in the presence of ${ }^{18} \mathrm{O}$-enriched water increases the mass difference to $2.984 \mathrm{Da}$, allowing for more confident identification of glycosylation site and its distinction from naturally occurring deamidation. Use of the method requires care, as concurrent incorporation of ${ }^{18} \mathrm{O}$ into $\mathrm{C}$-termini can lead to false positive identifications of glycosylation sites if residual trypsin is present [76].

Prior to MS analysis of glycans and glycopeptides, a series of preparative and enrichment methods are usually necessary that may include separation, extraction, and isolation from interferences in the sample such as non-glycosylated proteins, reagents, enzymes and cell lysate residues. Isolation of glycoproteins from samples can be done by 2D-gel electrophoresis, sodium dodecyl sulfate polyacrylamide gel electrophoresis (SDS-PAGE) and other chromatographic separation methods. If in need of information about glycosylation sites and amino acid sequence of glycopeptides, enzymatic digestion of glycoproteins and release of glycans (deglycosylation) need to be done either through in-solution methods or using reactor columns. Liquid chromatography (LC) [77] and capillary electrophoresis (CE) [78] methods can be used in enrichment of digested glycopeptides and released glycans. These preparative methods reduce the complexity of the sample, increase the abundance of glycopeptides and glycans, minimizes ionization suppression; therefore, they are considered as the limiting steps of successful glycan analysis. Finally, MS data are used in a database search of protein sequences to identify the glycans, peptides and consequently the protein origin (Figure 2).

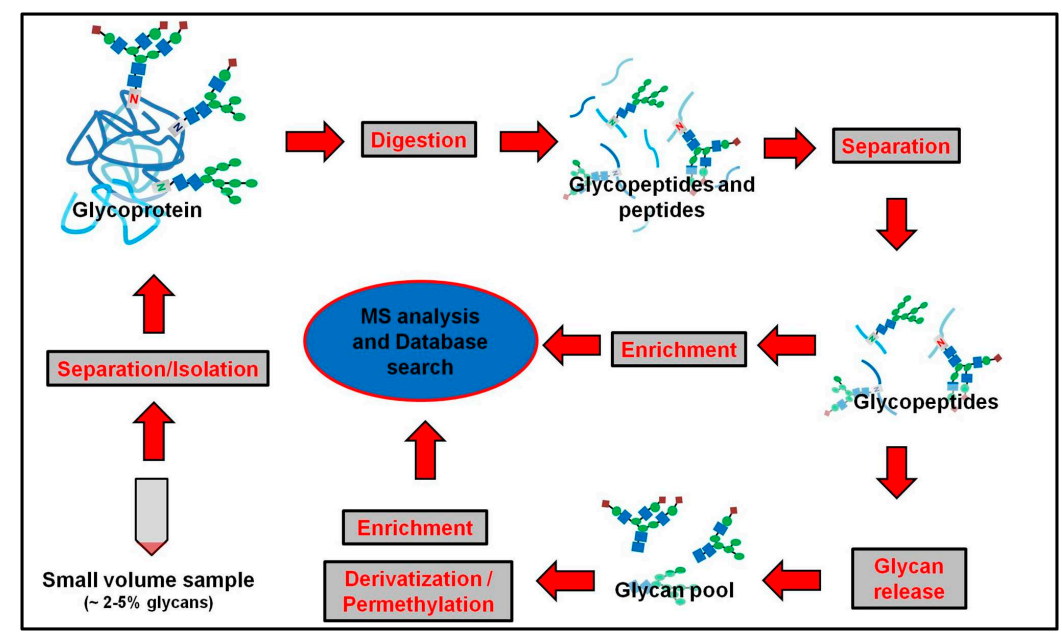

Figure 2. General work flow in glycomics. The over-all objective is to elucidate the structure of glycans and identify the glycosylation sites on the glycopeptides to determine the function of the attached glycans. One challenge in glycomics is the very small amount of glycans in the sample such as serum and other biological samples, tissue and plant extracts, and cultured cells. Therefore, a series of efficient preparative methods and enrichment are required prior to mass spectrometry (MS) analysis. 


\section{Monolithic Columns}

The invention and development of monolithic column materials was the outcome of the continuous effort to improve methods for faster and more efficient separations, biocatalysis and related applications. The progress of these materials can be summarized, starting with columns packed with uniformly sized porous particles that appear to have large interstitial spaces. These types of columns facilitate separation mainly based on diffusion of solutes from a more concentrated mobile phase to the stagnant phase inside the pores. Fluid carrying the solute tends to flow through the void spaces not reaching most of the surface inside the pores. Reducing the sizes of these particles is an option to diminish the functionless voids; however, packing of smaller particles reduces the permeability of the column developing high back pressure during the separation. Finally, a sophisticated design of an integrated and continuous network of flow-through pores was introduced forming a "one-piece" porous material currently called a "monolithic column" [79-81]. Monolithic columns are known to have these distinct and advantageous characteristics: (1) easy fabrication; (2) versatility for a variety of surface chemistries; and (3) good permeability that allows fast convective mass transfer with low backpressure even at high flow rates.

The following sections showcase the above mentioned characteristics of monolithic columns and how these are being utilized by recent and growing literature [82-124] in designing and developing preparative columns for glycan analysis.

\subsection{Monolithic Columns Can Easily Be Prepared In-Situ}

Though the preparation of a monolithic column is usually a trial-and-error procedure, the optimized prepared columns are relatively reproducible compared to packed columns. The common preparation is direct copolymerization, which is a very straightforward and convenient approach. This usually involves one-step copolymerization of monomers, cross-linker, porogenic solvents and initiator in a column. Monolithic columns have been classified based on the precursor materials used in their fabrication: organic polymers, inorganic silica and hybrids of the two. Organic polymer-based and silica-based monoliths were characterized as to differences in morphology; therefore usually they are involved in exclusive functions. While the higher surface area of bimodal pore structure of silica-based monoliths showed good performance in separation of small molecules, the interconnected microglobules structure of organic polymer-based monoliths is usually reported to provide good separations of large molecules like proteins, nucleic acids and synthetic polymers (Figure 3). Silica-based monoliths show more rigidity and mechanical stability to organic solvents and have higher surface area for immobilization of ligands. Organic polymer-based monoliths, on the other hand, such as those made of polymethacrylate, polyacrylamide and polystyrene have good biocompatibility and excellent stability over a wide range of $\mathrm{pH}$.

In 1989, Hjertén et al. introduced the use of continuous polymer beds in high performance liquid chromatography [81]. Tennikova et al. designed and prepared the organic polymer-based monolithic column in 1991 [79]. The polymerization mixture is usually sealed into a microcolumn, allowed to polymerize by exposure to UV light or by keeping at a certain temperature followed by flushing out excess reagents and solvents [125]. The silica-based monolithic column was introduced by Tanaka et al. in 1996 [126]. These columns were prepared by the sol-gel method, i.e., hydrolysis and polycondensation of alkoxysilanes catalyzed by an acid in the presence of a porogenic solvent [127]. Hybrid monoliths 
combined silica and organic polymer monoliths via either sol-gel [128] or a one-pot process [129]. A one-pot process is the simultaneous use of organic monomers and alkoxysilanes. Other inorganic monoliths complete the list of monolithic materials for separations [3]. Carbon-based monolithic columns with a highly interconnected bimodal porous structure were developed and used in HPLC separation with low hydraulic resistance [130]. Our laboratory is currently developing nanoporous gold monoliths as substrates in protein separation by modifying its surface with thiolated compounds forming self-assembled monolayers [131,132]. There are now commercially available monolithic separation columns such as silica-based Chromolith ${ }^{\circledR}$ HPLC columns [133] and styrene polymer-based ProSwift ${ }^{\mathrm{TM}}$ reverse-phase (RP) columns [134]. Several reviews have summarized materials used in preparation of monolithic columns in various applications [135-138] and the properties of monolithic materials and surface modifications [139-141].
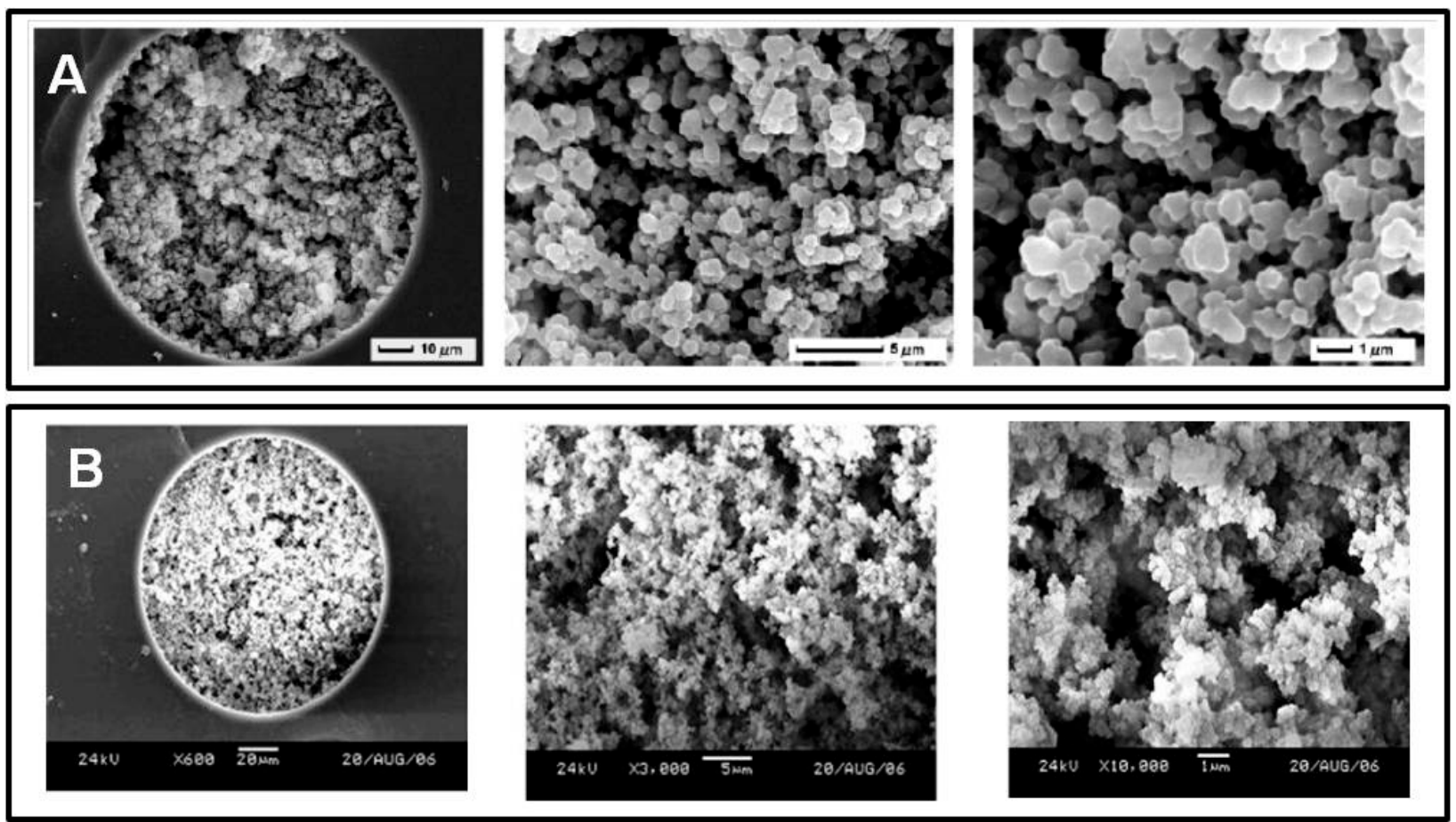

Figure 3. Scanning electron micrographs of the cross-section of monoliths. (A) Organic polymer-based monolith has interconnected microglobule structure mostly used in separation of large molecules such as proteins, nucleic acids and synthetic polymers (magnification: $\times 1000, \times 2000, \times 5000$, from left to right, respectively). Reprinted with permission from reference [142]. (B) Hybrid silica-based monolith has bimodal pore structure mostly used in separation of small molecules (magnification: $\times 600, \times 3000$, $\times 10000$, from left to right, respectively). Reprinted with permission from reference [143].

The majority of the reported monolithic columns for separation and analysis of glycans are organic polymer-based [82-87,89,90,92-95,97-104,107-112,114,115,118-121,123,144-146]. This may be due to the straightforward approach in the preparation and the availability of a variety of functional monomers to obtain desired functionality of the surface. Methacrylate-based glycidyl methacrylate (GMA) is the most commonly used co-monomer [147]. The reactive epoxy group of GMA allows easy post-modification by various reagents. Ethylene dimethacrylate (EDMA) is a popular cross-linker due 
to its ability to produce rigid macroporous polymers. The desired morphology of a monolith is obtained by varying the composition and reaction conditions such as temperature and reaction time. For example, the porous structure of polymeric monoliths are greatly influenced by the properties of the porogenic solvents and their proportion to the monomers [136].

Monolithic materials are contributing a big leap in the advancement of column technology, particularly in designing miniaturized columns for the separation of samples available in small amount and those species present only at trace levels. In situ direct synthesis allows preparation of monolithic materials within capillaries and very narrow channels of microfluidic devices [148]. This provides a lower mass limit of detection that could enhance the sensitivity of the analysis. In recent years, monolithic columns and stationary phases are involved in microscale chromatographic separation such as capillary liquid chromatography (CLC), capillary electrochromatography (CEC), and microfluidic devices [149]. Fused silica capillaries with inner diameter that ranges from $75 \mu \mathrm{m}$ to $530 \mu \mathrm{m}$ were the most commonly used packing material in these monolithic columns [82-85,87-94,96,98,99,102-105, 107-110,114,115,117-120,123,144]. Other types such as stainless steel tube [95,111,121], poly(etherether-ketone) (PEEK) column [146], pipette tips [100,101] and syringe [106] have also been reported.

\subsection{Monolithic Columns Are Versatile to a Variety of Available Surface Modifications}

Monolithic materials become versatile and selective in separations and other related applications because of the wide range of surface modifications they can undergo. Monolithic materials are used as stationary phases in several chromatographic processes in different modes such as reverse phase (RP)/hydrophobic, normal phase (NP)/neutral polar/hydrophilic, ion-exchange, affinity, and size exclusion. The two common modification methods of monolithic columns are direct copolymerization and post-modification. Direct copolymerization is the method wherein the desired functional groupcarrier monomer is added during the fabrication steps. However in this method, there are cases such that functional groups are not fully accessible and end up being buried after the polymerization. Postmodification, on the other hand, utilizes active sites in the polymerized parent monolith such as epoxides of an organic polymer GMA-based monolith and the siloxane of silica-based materials. However in this method, the amount of active sites in the parent monoliths may limit the effectiveness of the postmodified monolith. Also, there is a tendency to create a mixed mode of the matrix that may produce secondary interactions that can interfere in efficient separations [140].

In preparation of preparative columns for analysis of glycans, various direct and post modifications of surfaces were also employed. A popular direct modification method was incorporation of functional monomers or compounds in the polymerization mixture to achieve desired functionality of the matrix. Examples include alkyl compounds [87], ([2-(methacryloyloxy)ethyl]trimethyl-ammonium chloride (MAETA) [120], and 4-vinylphenylboronic acid (VPBA) [102,103,144] to provide hydrophobic, cationic and boronic acid functionality, respectively. Metal-organic gels (MOGs), Fe ${ }^{\mathrm{III}}$-BTC gels, were also added to the polymerization mixture to produce positively charged monoliths [111]. An example of post-modification was photografting of hydrophilic polymer poly(ethyleneglycol) methacrylate (PEGMA) to reduce the hydrophobicity of the monolith [82]. To create affinity mode, lectins were immobilized on the surface in various ways such as covalent binding of amine residues to aldehydefunctionalized surfaces [84,98,115,117,119-121], chelation to (IDA-Cu ${ }^{2+}$ ) modified surfaces [99] and a 
molecular imprinting method using a polydopamine coating [112]. Coating a monolith surface with nanoparticles provides a high loading of functional groups, fixing the problem of limited active sites described above. Monoliths were coated with $20 \mathrm{~nm}$ gold nanoparticles and further functionalized with the linker 3,3'-dithiodipropionic acid di(N-hydroxysuccinimide ester) (DTSP) to immobilize lectin [100]. Amine functionalized-latex beads $(60 \mathrm{~nm})$ coated monoliths were used in micro anion-exchange chromatography [97].

\subsection{Monolithic Columns Have High Permeability and Provide Excellent Mass Transfer with Low} Backpressure

A monolithic column provides high permeability with no interstitial voids or unwanted channels. These characteristics minimize the inconsistencies in column-to-column chromatographic separations. The continuous structure of monolithic materials forces mobile phases to go through the pores enhancing the mass transfer due to convective interaction through the pores rather than diffusion of analytes into pores. Packed columns use frits to hold the particulate beads in the columns. Monolithic columns, being polymerized in situ, need no frits and therefore avoid clogging by sample contaminants [150]. The use of fritless columns can also help overcome problems with gas bubble formation, known to be an issue in CEC and able to disrupt electro-osmotic flow (EOF) [151]. Frit formation does not have good reproducibility, and the process of frit formation can render columns fragile and generate voids in the packed bed [152]. Frits also pose special problems for CEC coupled with MS detection, since the end of the capillary exposed to the nebulizer cannot be pressurized [153]. In preparative analytical methods like separation, monolithic columns enhance the convective mass transfer with a reduced diffusion effect resulting to faster and more efficient separations [154]. In solid-phase synthesis and in designing enzyme reactors, monolithic platforms offer greater loading capacity and more accessible immobilized enzymes on the surface.

\section{Development of Monolithic Column Materials Used in Glycan Release, Separation and Analysis of Glycans}

The following discussion will focus on reports of research that developed monolithic stationary phases and matrices, which include microcolumns, capillaries and narrow channels in digestion and deglycosylation of glycoproteins and glycopeptides; and in separation, isolation and enrichment of glycans, glycopeptides and glycoproteins.

\subsection{Monolithic Reactor Columns in Digestion of Glycoproteins and Deglycosylation of Glycopeptides}

Glycoproteins, due to their relative low efficiency of ionization and fragmentation like all other proteins, usually need to be digested into smaller peptides prior to MS analysis. Furthermore, release of glycans from digested peptides is also necessary if glycosylation sites are sought in the analysis. Peptide digestion is mostly done by enzymatic digestion using proteases like trypsin. For procedures in proteomics aimed at identification of protein, deglycosylation prior to trypsin digestion can increase the confidence of protein identification, and increase MS signal intensities. However in glycoproteomics, deglycosylation prior to protease digestion can improve the quality of proteome analysis [155]. Release of glycans from peptides uses endoglycosidases such as peptide N-glycosidase F (PNGase F). PNGase 
$\mathrm{F}$ hydrolyzes and cleaves the linkage between asparagines and $\mathrm{N}$-acetylglucosamine liberating $\mathrm{N}$-glycans from the peptides and resulting in conversion of the asparagine to aspartic acid by deamidation [156]. PNGase F will not remove glycans containing $\alpha$ (1-3)-linked core fucose [157]. The conventional enzymatic in-solution digestion and deglycosylation takes several hours or even overnight to complete the process. This is because a low concentration of trypsin should be maintained to avoid autolysis that produces digests of the enzymes that affect the purity of the sample, and so the efficiency of the process. An efficient and alternative method is to immobilize trypsin on a solid support to create flow-through reactors that can speed up the process. In addition to flow-through reactors, it is also possible for flow of protein solution to be paused in a reactor to allow for digestion with the flow then resumed [158,159]. Autolysis is minimized when the enzymes are immobilized in enzyme reactors [142]. High density enzyme immobilized to these reactors increases the enzyme-to-substrate ratio, therefore capable even with samples of low concentration [160-162]. Moreover, enzymes like PNGase F are expensive such that the use of solid support could be relatively economical. Immobilization of trypsin into beads and channels of microfluidic devices [163] and capillaries [164] were reported. Monolithic enzyme reactors can be coupled to MS and separation columns, an opportunity for automated, on-line multidimensional systems. Monolithic enzyme reactors that showed enhanced enzyme activity, i.e., faster, higher loading density of enzymes and economical were showcased in recent research works (Table 1). Reactors that showed poor performance due to slow enzymatic reactions and low density of immobilized enzymes were aided by optimized immobilization conditions and addition of organic solvent, e.g., acetonitrile (ACN) in buffer to prevent non-specific adsorption. Enzyme immobilization is greatly influenced by the protein dynamics and substrate accessibility. Digestion efficiency, which is maximized when trypsin acts on all of the available cleavage sites, can be enhanced by denaturation of the target protein by use of aqueous-organic solvent systems containing methanol, isopropanol or ACN. Such enhanced digestion efficiency can improve sequence coverage [164,165].

Monolithic capillary enzyme reactors with immobilized trypsin showed highly efficient digestion of both the small protein cytochrome $c$ (cyt $c$ ) and the large protein human immunoglobulin G (hIgG). The most significant advantage of this reactor was the efficient digestion even of high-molecular weight $\mathrm{hIgG}$, which was digested within four min at room temperature. This was much faster compared to a $24 \mathrm{~h}$, $37^{\circ} \mathrm{C}$ in-solution method. The monolithic reactors maintained their activity for at least $80 \mathrm{~h}$ while being kept in a refrigerator for six months [82]. The same monolithic capillary was further used to immobilize PNGase F that was able to deglycosylate RNase B 400× faster than in-solution at room temperature. The monolithic reactor was operational for a total of $40 \mathrm{~h}$ over two months [83]. Likewise, in another study, a PNGase F monolithic microreactor was able to deglycosylate glycoproteins within only six min with a loading capacity of 2 pmol [84]. Small-scale deglycosylation of small to medium sized glycoproteins was done using a microreactor that was able to remove N-glycans at submicrogram level in a much shorter reaction time of 3.5 min compared to $18 \mathrm{~h}$ incubation in solution and was still good to use for up to eight weeks [85]. One study enhanced the efficiency of the monolithic microreactor by oriented immobilization of PNGase F (PNGase F-GST) to glutathione-functionalized surfaces via site-specific GSH-GST binding. Using this monolithic reactor, complete deglycosylation of $2.5 \mathrm{mg} \mathrm{mL}^{-1}$ RNase B was achieved in $15 \mathrm{~s}$, much faster than the one prepared with non-specific immobilization of enzyme, which lasted for minutes. The improvement was suggested as due to permeability of the monolithic support that enhanced the speed [86]. 
Table 1. Monolithic enzyme reactor columns used in digestion and deglycosylation of glycoproteins and glycopeptides.

\begin{tabular}{|c|c|c|c|c|c|c|c|c|}
\hline \multirow[t]{2}{*}{ Column } & \multirow[t]{2}{*}{$\begin{array}{c}\text { Immobilization } \\
\text { Method }\end{array}$} & \multirow[t]{2}{*}{ Application } & \multicolumn{2}{|c|}{ Amount of Enzyme Used * } & \multicolumn{2}{|c|}{$\begin{array}{c}\text { Reaction Time and } \\
\text { Temperature }\end{array}$} & \multirow[t]{2}{*}{ Stability } & \multirow[t]{2}{*}{ Ref. } \\
\hline & & & In-solution & $\begin{array}{l}\text { Monolithic } \\
\text { reactor }\end{array}$ & In-solution & $\begin{array}{l}\text { Monolithic } \\
\text { reactor }\end{array}$ & & \\
\hline $\begin{array}{l}\text { Trypsin reactor } \\
\text { LysC reactor }\end{array}$ & $\begin{array}{l}\text { Via grafted vinyl } \\
\text { azlactone (VAL) }\end{array}$ & $\begin{array}{l}\text { Digestion of hIgG } \\
\text { Digestion of hIgG }\end{array}$ & $\begin{array}{l}\text { Substrate-to- } \\
\text { enzyme ratio of } \\
50: 1(\mathrm{w} / \mathrm{w}) \text { with } \\
1.25 \mathrm{mg} / \mathrm{mL} \text { protein }\end{array}$ & $2.5 \mathrm{mg} / \mathrm{mL}$ & $\begin{array}{l}24 \mathrm{~h} ; \\
37^{\circ} \mathrm{C} \\
24 \mathrm{~h} ; \\
37^{\circ} \mathrm{C}\end{array}$ & $\begin{array}{c}4 \mathrm{~min} \\
22^{\circ} \mathrm{C} \\
6.2 \mathrm{~min} \\
22^{\circ} \mathrm{C} \\
\end{array}$ & 6 months & [82] \\
\hline $\begin{array}{l}\text { PNGase F } \\
\text { reactor }\end{array}$ & $\begin{array}{l}\text { Via grafted vinyl } \\
\text { azlactone (VAL) }\end{array}$ & $\begin{array}{l}\text { Deglycosylation of } \\
\text { hIgG integrated } \\
\text { on-line with HILIC } \\
\text { mode separation and } \\
\text { ESI-MS }\end{array}$ & $0.5 \mu \mathrm{L}$ & $\begin{array}{l}0.1 \mu \mathrm{L} / \mathrm{min} \\
\text { for } 2.5 \mathrm{~h}\end{array}$ & $\begin{array}{l}24 \mathrm{~h} ; \\
37^{\circ} \mathrm{C}\end{array}$ & $\begin{array}{l}5.5 \mathrm{~min} ; \\
\text { room } \\
\text { temperature } \\
\quad(\mathrm{RT})\end{array}$ & 2 months & [83] \\
\hline $\begin{array}{l}\text { PNGase F } \\
\text { reactor }\end{array}$ & $\begin{array}{l}\text { Via aldehydes } \\
\text { (oxidized } \\
\text { epoxides) }\end{array}$ & $\begin{array}{l}\text { Simultaneous on-line } \\
\text { release and analysis } \\
\text { of acidic and neutral } \\
\mathrm{N} \text {-glycans from } \\
0.1 \mu \mathrm{L} \text { human serum }\end{array}$ & NS ** & NS $* *$ & $\begin{array}{l}\text { Overnight; } \\
37^{\circ} \mathrm{C}\end{array}$ & few min; RT & NS ** & [84] \\
\hline $\begin{array}{l}\text { PNGase F } \\
\text { micro-reactor }\end{array}$ & $\begin{array}{l}\text { Via direct } \\
\text { co-polymerization }\end{array}$ & $\begin{array}{l}\text { Small scale } \\
\text { deglycosylation of } \\
\text { N-linked } \\
\text { glycoproteins }\end{array}$ & $5 \mu \mathrm{L}$ of $1 \mathrm{mg} / \mathrm{mL}$ & $\begin{array}{c}1 \mu \mathrm{L} \text { of } \\
1 \mathrm{mg} / \mathrm{mL}\end{array}$ & $10 \mathrm{~h} ; 37^{\circ} \mathrm{C}$ & $\begin{array}{l}3.5 \mathrm{~min} \\
21-23^{\circ} \mathrm{C}\end{array}$ & 8 weeks & [85] \\
\hline $\begin{array}{l}\text { PNGase F } \\
\text { reactor }\end{array}$ & $\begin{array}{l}\text { Oriented } \\
\text { immobilization via } \\
\text { site-specific } \\
\text { GSH-GST binding }\end{array}$ & $\begin{array}{l}\text { More efficient } \\
\text { deglycosylation of } \\
\text { hIgG }\end{array}$ & $1 \mathrm{mg} / \mathrm{mL}^{* * *}$ & $1 \mathrm{mg} / \mathrm{mL}$ & $\begin{array}{c}2 \mathrm{~h} ; \\
37^{\circ} \mathrm{C} * * *\end{array}$ & $15 \mathrm{~s} ; \mathrm{RT}$ & 5 months & {$[86]$} \\
\hline
\end{tabular}

* Amount of enzyme used as mentioned in methods of the cited literature (concentration of enzyme is that of the prepared enzyme solution to which the monolith was exposed during preparation; volume of enzyme is that of the prepared enzyme solution used with a certain activity. $* *$ Not specified. $* * *$ Enzyme was also immobilized in monolithic reactor but not in an oriented manner as described. 
PNGase $\mathrm{F}$ is a significantly more expensive enzyme than unmodified trypsin. Whereas $100 \mathrm{mg}$ of lyophilized trypsin from bovine pancreas costs $<\$ 50$, a sample in buffer of just 50 units of activity of PNGase $\mathrm{F}$ (one unit is defined as catalyzing the release of $\mathrm{N}$-linked glycans from 1 nanomole of denatured ribonuclease $\mathrm{B}$ in one minute at $37^{\circ} \mathrm{C}$ and $\mathrm{pH}$ 7.5, as monitored by SDS-PAGE.) costs about $5 \mathrm{X}$ this amount. For use of PNGase F supplied in buffer $\left(10,000\right.$ units $\left.\mathrm{mL}^{-1}\right)$, a typical protocol calls for combining $50 \mu \mathrm{g}$ of protein with $2 \mu \mathrm{L}$ PNGase F solution (20 units of activity) at $37{ }^{\circ} \mathrm{C}$ for $1-3 \mathrm{~h}$ under denaturing conditions, or $20 \mu \mathrm{g}$ of protein with this amount under non-denaturing conditions for $2-18 \mathrm{~h}$. In solution, trypsin to protein ratios between 1:20 and 1:100 are typically used. To minimize autolysis in solution, modified trypsin, subjected to reductive methylation, may be preferred, and is significantly more costly than unmodified trypsin [166]. In the preparation of the trypsin reactor introduced by Palm and Novotny [161], $1 \mu \mathrm{L}$ of a $20 \mu \mathrm{g} \mathrm{mL}^{-1}$ solution of trypsin in buffer (20 $\mu \mathrm{g}$ of enzyme) was used to prepare a reactor $6 \mathrm{~cm}$ in length. For preparation of a PNGase F reactor of the same length using a similar procedure by this group, $1-4 \mu \mathrm{L}$ of a solution of ca. $1 \mu \mathrm{g} \mathrm{mL} \mathrm{m}^{-1}$ enzyme in buffer was required (1-4 $\mu \mathrm{g}$ of enzyme, 25-100 units of activity) [161]. As noted in Table 1, immobilized enzyme reactors have finite lifetimes typically in a range of 2-6 months. While impressive increases in sample digestion or deglycosylation rate have been achieved, immobilized enzyme reactors may suffer from challenges including non-specific protein adsorption and a need to continue to improve their repeatability and robustness [167]. Minimization of non-specific adsorption by use of more hydrophilic supports can enhance recovery of digested peptides providing more sample for analysis.

Deglycosylation of N-glycosylation sites by action of PNGase F in the presence of ${ }^{18} \mathrm{O}$-enriched water does not seem to have yet been reported using an immobilized PNGase F reactor. This could be achieved by placing a trypsin reactor in sequence with a PNGase F reactor, provided that issues with transferring the glycopeptides produced by the trypsin reactor into ${ }^{18} \mathrm{O}$-enriched water prior to introduction into the PNGase F reactor could be resolved. The use of ${ }^{18} \mathrm{O}$-enriched water in the trypsin reactor would lead to the complication of ${ }^{18} \mathrm{O}$ labeling of C-termini. A disadvantage would be the increased cost of using ${ }^{18} \mathrm{O}$-enrich water. Recently, an integrated strategy of lectin affinity separation, followed by passage through immobilized trypsin, quenching of residual trypsin, and PNGase $\mathrm{F}$ catalyzed ${ }^{18} \mathrm{O}$ labeling was introduced [168]. In this case, ${ }^{18} \mathrm{O}$ labeling of the $\mathrm{C}$-termini (4 Da shift) was done in addition to ${ }^{18} \mathrm{O}$ labeling of the glycosylation site (to give a total $6 \mathrm{Da}$ shift). Equal amounts of labeled and unlabeled glycopeptides were then subjected to LC-ESI-MS/MS analysis. This approach suggests that the presence of ${ }^{18} \mathrm{O}$-enriched water in both reactors may be suitable for producing the labeled samples. Efficient and stable trypsin immobilization to avoid the issue of residual trypsin contamination would be required.

The significance of monolithic columns was initially showcased in separation and biocatalysis by Svec and Frechet in 1996 [141]. Monolith pore sizes most usually fall in the IUPAC categories of mesoporous (pore size $=2-50 \mathrm{~nm}$ ) and macroporous (pore size $>50 \mathrm{~nm}$ ), and both types of pores may be present. The porous structure provides rapid convectional mass transport with lower backpressure. In a tight sealed column, backpressure can be defined as the opposing force to the flow. This characteristic makes monolithic columns new generation media for faster and more efficient separations. 


\subsection{Monolithic Columns in Separation and Enrichment of Glycoproteins, Glycopeptides and Glycans}

Separation of glycans and glycoproteins can be either a pump-driven liquid chromatography (LC) or an electric field-driven electrophoresis (CE). LC separation is due to the difference in the extent of interactions of the solutes in the mobile phase with the functionalized stationary phase. Pore structure and sizes greatly affect the LC flow. Unlike LC, CEC is independent of channel or pore diameter and the separation is due to the difference in mass-to-charge ratio $(\mathrm{m} / \mathrm{z})$ of the solutes upon passing high voltage across the matrix. Combining the chromatographic flow of LC and mobile phase migration mode of CE resulted to an efficient method called capillary electrochromatography (CEC). High column efficiency at faster velocity separation of glycans was achieved in CEC using monolithic columns. For example, CEC separation with polar stationary phase and use of ion trap MS can resolve glycan isomers, one of the most challenging goals in analysis of glycan structure because they usually give identical or very similar MS spectra.

The mobile phase should give an appropriate environment to the analyte by tuning its $\mathrm{pH}$, ionic strength, organic solvent content and presence of analyte modifiers. This complements the functionality of the stationary phase that dictates the mode of separation. Different modes of separation of glycans can be characterized by different interactions between the bound ligands on the surface and the glycans. These include: (1) interactions between hydrophobic surface and hydrophobic labels of derivatized glycans; (2) H-bonding between the neutral polar surface and $\mathrm{OH}$ groups of glycans; (3) electrostatic interactions between charged (cationic) surface and negatively charged ionized glycans; anionic terminal sialic acids or labels of derivatized glycans; and (4) affinity between immobilized lectins and its complementary glycan structure or between boronic acids on the surface and cis-diols of glycans (Figure 4).

\subsubsection{Reverse-Phase Mode}

Reverse-phase separation (RP-LC) uses a hydrophobic stationary phase and a polar mobile phase to separate biomolecules by the differences in the extent of hydrophobic interactions between the biomolecules and the stationary phase, thus the more hydrophilic molecules are eluted first in this method. Unless they are derivatized, neutral glycans are retained very weakly on the commonly used C18 stationary phase [77]. Some of the small molecular tags for modification of carbohydrates are 2-aminobenzamide (2-AB), 2-aminopyridine (2-AP), and 2-aminobenzoic acid (2-AA), amongst many others designed to enhance separation or increase the signal for fluorescence detection [169]. Labeling with 2-AP was first introduced by Hase in 1978 [170,171]. Permethylation of glycans can also be used to enable separation by RP-LC [172]. Labeling provides the hydrophobic interactions needed for retention and separation by the reversed phase column, and also a chromophore for enabling detection. If the hydrophobic tag is too large, then differences between glycan structures may not be resolved [173]. These methods are most typically applied to glycan pools released from one or more glycoproteins. Methods for derivatizing glycans for separation and analysis have been reviewed [26,169]. A potential advantage of RP-LC is that the solvent used (water + organic solvent + acid) is compatible with mass spectrometry analysis [174]. 8-aminonaphthalene-1,3,6-trisulfonic acid (ANTS) can be used a label for charged glycans in a method known as reversed-phase ion-pairing liquid chromatography [175]. Some glycans that co-elute in normal phase LC can be separated by RP-LC after derivatization [176]. As an 
alternate to standard RP-LC stationary phases, a hydrophobic polyacrylamide/PEG monolithic column modified with alkyl chains was prepared for RP-CEC separation of 2-AB labeled maltooligosaccharides at lower $\mathrm{pH}(<4.0)$ with detection by laser-induced fluorescence [87].

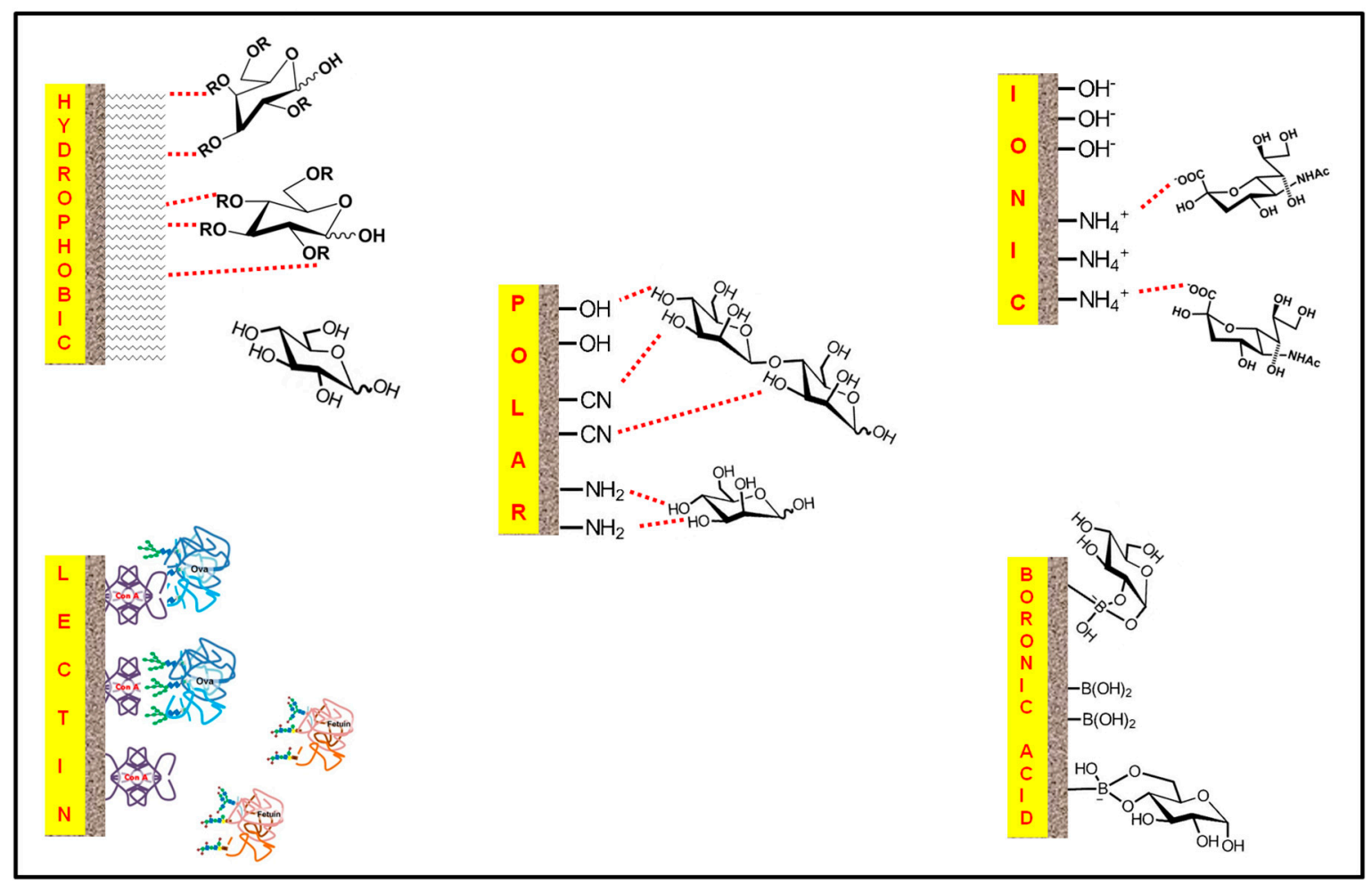

Figure 4. Different modes of separation using functionalized monolithic columns. Hydrophobic mode with C18 ligands that interact with hydrophobic labels of modified sugar units; polar mode with hydroxyl, cyano or amino ligands that interact with the $\mathrm{OH}$ groups of glycans; electrostatic mode with charged ligands that either attract or repel negatively charged terminal sialic acids, deprotonated glycans at high $\mathrm{pH}$ and charged residues of glycopeptides and glycoproteins; affinity modes with immobilized lectins that specifically bind to glycan structures of glycoproteins via non-covalent interactions and boronic acids that covalently form cyclic esters with the cis-diol moieties of glycans.

\subsubsection{Polar Mode}

The mechanism of polar mode separations involves H-bonding and dipole-dipole interactions between polar stationary phase and $\mathrm{OH}$ groups of neutral glycans. In contrast to reverse-phase mode, the mobile phase is less polar than the stationary phase. Therefore, less polar glycans are eluted first and separation is achieved based on differences in glycan hydrophilicity. It is possible with this method to analyze neutral and charged glycans together [177]. Polar mode is also referred to as normal phase mode. One popular example of polar mode is the zwitterionic-hydrophilic interaction liquid chromatography (ZIC-HILIC or simply HILIC) [178]. Polar stationary phases may contain amino-, cyano-, amido-, or diol- functional groups. These are suitable for CEC separations, because with the right mobile phase, they provide a charged matrix that creates electro-osmotic flow (EOF) [179]. The mobile phase significantly affects the quality of separation in polar mode [180]. Ionic strength and $\mathrm{pH}$ of the mobile phase can be 
controlled by addition of ionic additives such as ammonium formate and ammonium acetate [181]. Added salts increase the polarity of the mobile phase and affect the separation [182]. The ionic strength and $\mathrm{pH}$ will have a more significant effect on the separation of sialylated glycans than on neutral glycans. The salts used in normal phase mode are volatile and compatible with MS analysis. Likewise, addition of organic solvent, e.g., ACN increases the retention of neutral glycans on HILIC columns [183]. Organic solvent also suppresses the secondary hydrophobic effect of the monolithic backbone. However, organic solvents may cause denaturation of proteins and could lead to precipitation and clogging of the column.

A hydrophilic silica monolithic column with $\mathrm{OH}$ functional groups was used in CEC separations of glycans. Using test molecules, the selectivity was found to be dependent on the position of the hydroxyl groups, i.e., ortho-substituted phenol had stronger interaction than para-substituted. In testing maltooligosaccharides, as the number of glucose units was increased, the retention of the analyte increased due to more solute polar sites. Increasing the ACN content of the mobile phase increased the selectivity of the polar stationary phase and was able to discriminate a solute pair that differed only in the orientation of their hydroxyl groups at the $\mathrm{C} 4$ position called epimers, e.g., $\beta \mathrm{Gal}$ and $\beta \mathrm{Glc}$. The $\mathrm{OH}$ group at $\mathrm{C} 4$ position in the Gal residue had less interaction with the stationary phase than the $\mathrm{OH}$ group at $\mathrm{C} 4$ position in the Glc residue. The resolution was able to increase further by increasing the ACN content [88].

The diol functionality of a neutral/polar monolithic column was used in nano-LC separation of 2-AB derivatized $\mathrm{N}$-glycans released from ovalbumin (Ova) and $\alpha_{1}$-acid-glycoprotein (AGP). Hybrid and complex N-glycans of Ova differ in the number of polar sites. N-glycans of AGP, on the other hand, differ in the number sialic acids. Polarity of glycans increases with the degree of sialylation. Separation of these 2-AB derivatized N-glycans was enhanced with the addition of a small amount of sulfated $\beta$-cyclodextrin $(\beta-C D)$ as a modifier. Addition of sulfated $\beta$-CD in the mobile phase increased the retention of $2-\mathrm{AB}$ glycans due to inclusion complex formation between the $\beta-\mathrm{CD}$ and $2-\mathrm{AB}$ on the glycans. The $\beta-C D$ cavity is hydrophobic and sterically well-defined in nature, thus the nature of the glycan controls the extent of its complexation with 2-AB [184]. Addition of ACN enhanced the separation. CEC separation of sialylated N-glycans of AGP required lower amounts of ACN due to the negatively charged sialic acids that can accommodate fast separations [89].

An amino-functionalized polar polyacrylamide-based monolithic column was used to separate enzymatically cleaved 2-AB derivatized glycan residues of RNase B. Similarly, the retention was longer for glycans with more glucose units and the longer retention time was influenced by the amount of organic solvent in the mobile phase. However, due to poor mechanical stability, the column is limited only to CEC or low-pressure chromatography [90]. A hydrophilic monolithic silica capillary column with amino functional group was used in HILIC-ESI-MS/MS separation and highly sensitive detection of underivatized carbohydrates. The monolithic column provided three times faster separation when compared to particle-packed HILIC columns. The combination of the high efficiency HILIC mode of the prepared column and the sensitivity of ESI-MS/MS detection gave high sensitivity (LOD $=3.2 \mathrm{ng} \mathrm{mL} \mathrm{mL}^{-1}$, attomol level) in separation and identification of non-reducing underivatized saccharides. This approach was able to identify highly polar components of $50 \mathrm{~nL}$ plant extract samples [91].

A hydrophilic cyano-functionalized polar monolithic column was used to effectively separate a mixture of neutral glycans based on the number of hydroxyl groups and their orientation. Maltose, a reducing disaccharide eluted later than monosaccharides, and showed two peaks due to its anomericity ( $\alpha$ and $\beta$ ) 
due to mutarotation (Figure 5). The monolithic column was inserted into the nanospray needle of and coupled to ESI-ion trap MS. The set-up was capable to detect as low as femtomole concentration of neutral saccharides. An enhanced resolution was further obtained by using a higher content of organic solvent in the mobile phase [92].

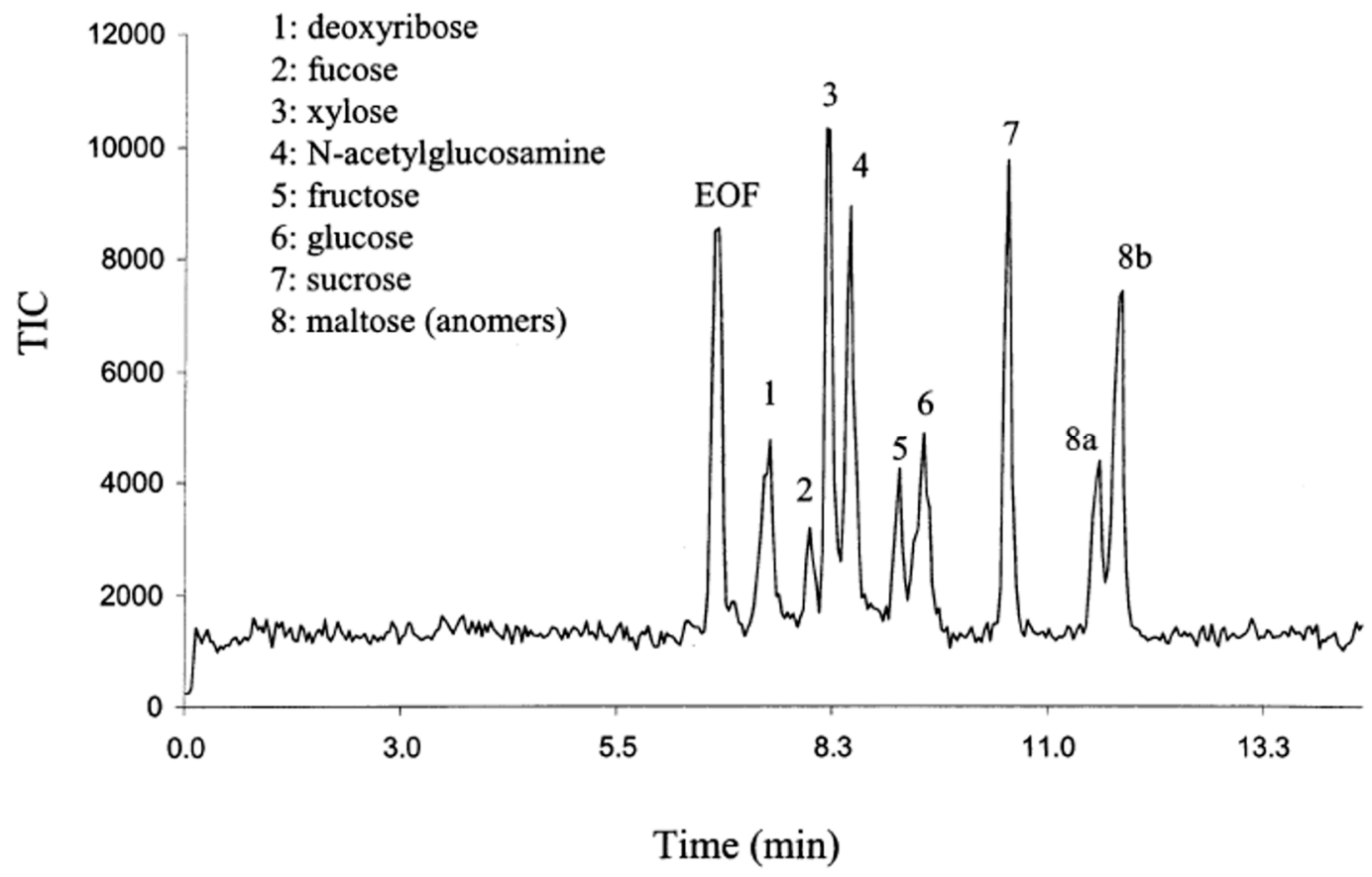

Figure 5. Electrochromatogram of a mixture of neutral and underivatized mono- and disaccharides that were capillary electrochromatography (CEC) separated using cyanomodified polar monolithic column. Reprinted with permission from reference [92].

Combination of advancement in MS analysis and polar mode CEC separation enhanced the capability of glycan analysis. For example, polar mode CEC separation coupled to ESI-MS/MS with the use of quadruple ion trap was used for on-line separation and analysis of isomeric oligosaccharides [93]. CEC coupled to electrospray Fourier transform MS (FT-MS) was utilized to resolve the complexity of large O-linked oligosaccharides derived from mucin and bile salt-stimulated lipase (BSSL) [94].

\subsubsection{Electrostatic Mode}

In the electrostatic mode of separation, retention is affected by the balance between the electrostatic attraction and repulsion between the solute and the matrix. The $\mathrm{pH}$ of the mobile phase influences the separation as it can modify the charge of the glycoproteins based on their isoelectric points (pI). Glycans are weak acids and are deprotonated at very high $\mathrm{pH}(>12)$ and become negatively-charged.

Hydrophilic monolithic column with diol $\mathrm{OH}$ groups was used to separate $\mathrm{IgG}$ from human plasma samples. Lowering the $\mathrm{pH}$ of the mobile phase increased the electrostatic interaction ( $\operatorname{IgG} \mathrm{pI}=6.85-8.5)$. IgG could be adsorbed on the monolithic column at a low $\mathrm{KH}_{2} \mathrm{PO}_{4}$ concentration and could be eluted with $\mathrm{K}_{2} \mathrm{HPO}_{4}$ [95]. A polymeric tris(2,3-epoxypropyl) isocyanurate and tri(2-aminoethyl)amine (poly(TEPIC-co-TAEA)) monolithic capillary was post-modified with ammonia solution to produce a mixture of $\mathrm{OH}$ (hydrophilic) and amino (cationic) functional groups that was used to separate glycoprotein 
isoforms at high resolution. Distinct protein isoforms were differentiated by the differences in $\mathrm{pI}$ values particularly at slightly higher $\mathrm{pH}$ [96]. Other work used an amine-functionalized polymeric monolithic column for high-performance anion-exchange chromatographic separation of underivatized carbohydrates at high $\mathrm{pH}$ with pulsed amperometric detection. The interaction was due to the weakly acidic nature of carbohydrates [97].

\subsubsection{Affinity Mode}

Affinity separation can be described by reversible interactions between matrix-bound ligands and specific sites of the glycans and glycoprotein. Purified glycan or glycoprotein is recovered from the matrix by rinsing with competitive ligands of higher affinity or alteration of the buffer system, i.e., change in $\mathrm{pH}$, ionic strength, or dwell time.

\subsubsection{Lectin Affinity}

Lectins are proteins that have conserved binding domains to selectively bind different glycans via non-covalent interactions such as H-bonding, electrostatic and van der Waals interactions. Depending on the $\mathrm{pH}$ of the solvent buffer, lectins can be dimeric or tetrameric, therefore they can exhibit multivalent binding with glycans. Lectins can be extracted and purified from plant or animal sources. In vitro, lectins are used in cell differentiation by probing the glycans on the surface of the cells being cultured or those that are present in the sectioned tissues of an organ of interest. Lectins, when immobilized to a solid support can maintain their biological properties such as binding to glycans [185]. Monosaccharides or hapten sugars can reverse the lectin-carbohydrate interactions and facilitate elution (Table 2). The specificity of lectins also leads to a need for use of multiple lectins in order to achieve more comprehensive glycoprotein/glycan analysis, as has been done using multi-lectin affinity columns. The stability of the lectin must be maintained in order for it to remain effective, and use of some less common lectins can become expensive. The buffer or $\mathrm{pH}$ conditions suitable for binding can vary substantially between specific lectins, for example binding by Concanavalin $A$ (Con A) requires the presence of $\mathrm{Ca}^{2+}$ and $\mathrm{Mn}^{2+}$ ions. On the other hand, the specificity of lectins can be used to capture and analyze a targeted group of glycoproteins such as those rich in terminal sialic acids.

Lectin affinity carried out in two steps, first to capture glycoproteins to a specific lectin and then to capture the digested glycopeptides, has been combined with in silico database analysis of the peptide sequences to simultaneously identify glycosylation sites and glycoprotein genes. This 'glyco-catch' method was applied using Con A and galectin LEC-6 to capture high mannose and complex glycans secreted by C. elegans [24]. WGA lectin affinity, for example, was used to enrich glycoproteins in serum samples and then gel electrophoresis and MS analysis was used to identify 39 differentially expressed proteins and suggested as possible biomarkers in lung cancer development and progression. WGA was found to capture more glycoproteins from the serum samples than six other lectins that were tested [186]. 
Table 2. Lectins immobilized in monolithic columns and used in affinity-based chromatographic separation of glycoproteins.

\begin{tabular}{|c|c|c|c|}
\hline Lectin & Haptenic sugar & Glycoproteins that binds to lectin & Ref. \\
\hline \multirow{4}{*}{$\begin{array}{l}\text { Concanavalin } A \\
\text { (Con A) }\end{array}$} & \multirow{4}{*}{$\begin{array}{l}\text { Methyl- } \alpha \text {-D- } \\
\text { mannopyranoside } \\
\text { (Me- } \alpha-D-M a n)\end{array}$} & Ribonuclease B (RNase B) & {$[98,101]$} \\
\hline & & Ovalbumin (Ova) & {$[101,120]$} \\
\hline & & Transferrin & [117] \\
\hline & & Horseradish peroxidase (HRP) & {$[120]$} \\
\hline \multirow{3}{*}{$\begin{array}{l}\text { Wheat germ agglutinin } \\
\text { (WGA) }\end{array}$} & \multirow{3}{*}{$\begin{array}{l}\text { N-Acetyl-D- } \\
\text { glucosamine (GlcNAc) }\end{array}$} & $\alpha_{1}$-acid glycoprotein (AGP) & {$[117,119]$} \\
\hline & & $\kappa$-Casein & [117] \\
\hline & & Fetuin & [119] \\
\hline \multirow{6}{*}{$\begin{array}{l}\text { Lens culinaris } \\
\text { agglutinin (LCA) }\end{array}$} & \multirow{6}{*}{$\begin{array}{l}\text { Methyl- } \alpha-\mathrm{D}^{-} \\
\text {mannopyranoside } \\
\text { (Me- } \alpha-\mathrm{D}-\mathrm{Man})\end{array}$} & Glucose oxidase (GOX) & {$[146]$} \\
\hline & & Lipoxidase & \multirow[t]{5}{*}{ [119] } \\
\hline & & Human transferrin $(\mathrm{HT})$ & \\
\hline & & $\alpha_{1}$-acid glycoprotein (AGP) & \\
\hline & & Avidin & \\
\hline & & Collagen & \\
\hline \multirow{2}{*}{$\begin{array}{l}\text { Erythrina cristagalli } \\
\text { lectin (ECL) }\end{array}$} & \multirow[t]{2}{*}{ Galactose } & Desiaylated transferrin & \multirow[t]{2}{*}[100]{} \\
\hline & & Desiaylated thyroglobulin & \\
\hline \multirow{2}{*}{$\begin{array}{l}\text { Sambucus Nigra lectin } \\
\text { (SNA) }\end{array}$} & \multirow[t]{2}{*}{ Sialic acid } & Fetuin & \multirow[t]{2}{*}[124]{} \\
\hline & & Oruscomucoid & \\
\hline
\end{tabular}

The immobilization of lectins on monolithic support was mostly done by covalent binding of amines on lysine residues to aldehyde-functionalized surfaces. An example was Con A lectin immobilized to a polymeric (GMA/EDMA) monolithic column capillary. GMA as mentioned above has epoxides that can be further oxidized to form aldehydes. This monolith was used as a nanospray emitter in ESI-MS/MS analysis of trypsin digest of RNase B. The combined enrichment with high selectivity of lectin affinity chromatography (LAC) and the sensitivity of nanoelectrospray tandem MS detection allowed identification of five glycoforms that was not attained without the enrichment process [98]. In other approach, Con A was immobilized by chelating it to $\mathrm{Cu}(\mathrm{II})$, then sandwiching it to IDA-derivatized monolith (EDMA:GMA-IDA-Cu(II)-Con A). This nanoscale Con A monolithic capillary utilized as little as $20 \mu \mathrm{L}$ of biological urine sample to be analyzed by nano-RPLC-ESI-MS. In comparison with conventional covalently immobilized Con A, it showed double the number of unique N-glycoproteins identified in human urine samples (37 out of 45 vs. 13 out of 16) using an IDA:Cu(II):Con A sandwich structure [99].

Another reported method of immobilization of ECL lectin was by coating the polymer with $20 \mathrm{~nm}$ gold nanoparticles functionalized by di(N-hydroxysuccinimide ester) (DTSP) linker and fabricated in a pipette tip. This was used as an extraction device to enrich galactosylated protein (desialyated transferrin) against RNase B [100]. Con A in another work was immobilized in a hydrophilic monolith prepared in 96 spin-tips and used to separate glycoproteins. This was proposed to be a straightforward, water-based, one-step approach that can be used in an up-scale process to economically efficient high volume columns [101] (see Table 3). 
Table 3. Summary of research works that use monolithic materials with different modes in separation, enrichment and analysis of glycans, glycoproteins and glycopeptides.

\begin{tabular}{|c|c|c|c|c|c|}
\hline Type of Flow & $\begin{array}{l}\text { Functional } \\
\text { Ligand }\end{array}$ & $\begin{array}{l}\text { Elution Method } \\
\text { (isoc. elu. = isocratic elution; } \\
\text { grad. elu. = gradient elution) }\end{array}$ & Applications & $\begin{array}{l}\text { Detection } \\
\text { Method }\end{array}$ & $\begin{array}{l}\text { Year \& } \\
\text { Ref. }\end{array}$ \\
\hline \multicolumn{6}{|c|}{ Reverse-phase mode } \\
\hline CEC & $\begin{array}{l}\text { Alkyl } \\
\text { ligands }\end{array}$ & $\begin{array}{l}\text { isoc. elu. } \\
5 \% \mathrm{ACN}\end{array}$ & $\begin{array}{l}\text { Separation of 2-AB derivatized maltooligosaccharides } \\
\text { (Glc4-Glc10) }\end{array}$ & $\begin{array}{l}\text { Laser-induced } \\
\text { fluorescence } \\
\text { detection }\end{array}$ & $\begin{array}{l}1997 \\
{[87]}\end{array}$ \\
\hline \multicolumn{6}{|l|}{ Polar mode } \\
\hline $\mathrm{CEC}$ & $-\mathrm{OH}$ & $\begin{array}{l}\text { isoc. elu. } \mathrm{pH} 4.5 \\
95 \% \mathrm{ACN}\end{array}$ & $\begin{array}{l}\text { Separation of nitrophenyl (ortho- or para-) derivatives of } \\
\text { mono- and oligosaccharides ( } \beta \mathrm{Gal} \text { and } \beta \mathrm{Glc} ; \beta \mathrm{GalNAc} \text { and } \\
\beta \mathrm{GlcNAc} \text { ) }\end{array}$ & $\begin{array}{l}\text { UV detector } \\
(304 \mathrm{~nm})\end{array}$ & $\begin{array}{l}2003 \\
{[88]}\end{array}$ \\
\hline CEC and LC & $-\mathrm{OH}$ & $\begin{array}{l}\text { isoc. elu. } \mathrm{pH} 6.0 \\
75 \% \text { or } 65 \% \mathrm{ACN} \\
+1 \mathrm{mM} \text { sulfated } \beta-\mathrm{CD}\end{array}$ & $\begin{array}{l}\text { Profiling of 2AB-derivatized N-glycans derived from Ova } \\
\text { and AGP }\end{array}$ & $\begin{array}{l}\text { UV detector } \\
(210 \mathrm{~nm})\end{array}$ & $\begin{array}{l}2009 \\
{[89]}\end{array}$ \\
\hline CEC & $-\mathrm{NH}_{2}$ & $\begin{array}{l}\text { isoc. elu. } \\
60 \% \text { ACN }\end{array}$ & $\begin{array}{l}\text { Separation and analysis of 2-AB derivatized glycans of } \\
\text { RNase B }\end{array}$ & $\begin{array}{l}\text { MALDI-TOF } \\
\text { MS }\end{array}$ & $\begin{array}{l}2006 \\
{[90]}\end{array}$ \\
\hline $\mathrm{LC}$ & $-\mathrm{NH}_{2}$ & $\begin{array}{l}\text { grad. elu. pH } 5.5 \\
90 \%-60 \% \text { ACN }\end{array}$ & $\begin{array}{l}\text { Separation of underivatized sugars (glucose, maltose, } \\
\text { maltotriose, maltotetraose, maltopentaose, maltohexaose, } \\
\text { maltoheptaose) } \\
\text { Sensitive detection of highly polar components (sucrose, } \\
\text { trehalose, maltose and some unknowns) of low volume ( } 50 \mathrm{~nL} \text { ) } \\
\text { sample extracts (corn, soybean, Arabidopsis thaliana leaf) }\end{array}$ & $\begin{array}{l}\text { ESI-MS } \\
\text { ESI-MS/MS }\end{array}$ & $\begin{array}{l}2008 \\
{[91]}\end{array}$ \\
\hline CEC & $-\mathrm{CN}$ & $\begin{array}{l}\text { isoc. elu. } \mathrm{pH} 3.0 \\
\text { (a) } 95 \% \text { or (b) } 80 \% \mathrm{ACN}\end{array}$ & $\begin{array}{l}\text { Separation of femtomole concentration of sugars as alditols: } \\
\text { (a) Monosaccharide alditols: fucitol, ribitol, xylitol, } \\
\text { N-acetylglucosaminitol, glucitol, and mannitol } \\
\text { (b) Disaccharide alditols: maltitol, cellobitol, lactitol, } \\
\text { and melibitol }\end{array}$ & $\begin{array}{l}\text { ESI-ion trap } \\
\text { MS }\end{array}$ & $\begin{array}{l}2002 \\
{[92]}\end{array}$ \\
\hline
\end{tabular}


Table 3. Cont.

\begin{tabular}{|c|c|c|c|c|c|}
\hline Type of Flow & $\begin{array}{l}\text { Functional } \\
\text { Ligand }\end{array}$ & $\begin{array}{l}\text { Elution Method } \\
\text { (isoc. elu. = isocratic elution; } \\
\text { grad. elu. = gradient elution) }\end{array}$ & Applications & $\begin{array}{l}\text { Detection } \\
\text { Method }\end{array}$ & $\begin{array}{l}\text { Year \& } \\
\text { Ref. }\end{array}$ \\
\hline \multicolumn{6}{|l|}{ Polar mode } \\
\hline CEC & $\begin{array}{l}-\mathrm{CN} \text { and } \\
-\mathrm{NH}_{2}\end{array}$ & $\begin{array}{l}\text { isoc. elu. } \mathrm{pH} 3.0 \\
65 \text { or } 70 \text { or } 75 \% \mathrm{ACN}\end{array}$ & $\begin{array}{l}\text { Separation of isomeric oligosaccharides: } \\
\text { (a) Linkage isomers } \\
\text { maltoheptaose }(\alpha 1 \rightarrow 4) \text { and Dextran DP7 }(\alpha 1 \rightarrow 6) \\
\text { (b) Compositional isomers of tetrasaccharides } \\
\text { Maltotetraose }\left[(\mathrm{Glc})_{4}\right] \text { and stachyose } \\
{[\mathrm{Gal}(1 \rightarrow 6) \mathrm{Gal}(1 \rightarrow 6) \mathrm{Glc}(1 \rightarrow 2) \mathrm{Fru}]} \\
\text { (c) Branch isomers of pentasaccharides } \\
\text { LNF I (linear) and LNF II (branched) } \\
\text { (d) Linkage anomers and reducing-end anomers } \\
\text { ( } \alpha \text { - and } \beta \text { - forms) } \\
\text { Maltopentaose and cellopentose standards } \\
\text { (e) High mannose, N-linked glycans derived from } \\
\text { RNase B } \\
\text { (f) O-linked glycans from bile-salt-stimulated lipase } \\
\text { (BSSL) }\end{array}$ & ESI-MS/MS & $\begin{array}{l}2002 \\
{[93]}\end{array}$ \\
\hline CEC & $-\mathrm{NH}_{2}$ & $\begin{array}{l}\text { isoc. elu. } \mathrm{pH} 3.0 \\
50 \% \mathrm{ACN}\end{array}$ & $\begin{array}{l}\text { Separation and analysis of O-glycans from bovine mucin } \\
\text { and bile-salt-simulated lipase (BSSL) }\end{array}$ & FTICR-MS & $\begin{array}{l}2003 \\
{[94]}\end{array}$ \\
\hline \multicolumn{6}{|c|}{ Electrostatic mode } \\
\hline $\mathrm{LC}$ & $-\mathrm{OH}$ & $\begin{array}{l}\text { grad. elu. } \mathrm{pH} 7.0 \\
100 \%-0 \% \mathrm{KH}_{2} \mathrm{PO}_{4}\end{array}$ & Separation of IgG from human plasma sample & $\begin{array}{l}\text { UV detector } \\
(280 \mathrm{~nm})\end{array}$ & $\begin{array}{l}2009 \\
{[95]}\end{array}$ \\
\hline CEC & $\begin{array}{l}-\mathrm{NH}_{2} \\
-\mathrm{OH}\end{array}$ & $\begin{array}{l}\text { grad. elu. } \\
\text { increasing amount of } \mathrm{NaCl}\end{array}$ & $\begin{array}{l}\text { High resolution profiling of glycoprotein isoforms (AGP, } \\
\text { Ova, } \alpha \text {-Fetal protein and human glycated hemoglobin) }\end{array}$ & UV detector & $\begin{array}{l}2011 \\
{[96]}\end{array}$ \\
\hline $\mathrm{LC}$ & $-\mathrm{NH}_{4}^{+}$ & $\begin{array}{l}\text { isoc. elu. } \mathrm{pH} 12.8 \\
64 \mathrm{mM} \mathrm{NH}_{4} \mathrm{OH}\end{array}$ & $\begin{array}{l}\text { Separation of sugars (maltotriose, maltose, and glucose) } \\
\text { derived from corn starch }\end{array}$ & $\begin{array}{l}\text { Pulse } \\
\text { amperometric } \\
\text { detection }\end{array}$ & $\begin{array}{l}2004 \\
{[97]}\end{array}$ \\
\hline
\end{tabular}


Table 3. Cont

\begin{tabular}{|c|c|c|c|c|c|}
\hline Type of Flow & $\begin{array}{l}\text { Functional } \\
\text { Ligand }\end{array}$ & $\begin{array}{l}\text { Elution Method } \\
\text { (isoc. elu. = isocratic elution; } \\
\text { grad. elu. = gradient elution) }\end{array}$ & Applications & $\begin{array}{l}\text { Detection } \\
\text { Method }\end{array}$ & $\begin{array}{c}\text { Year \& } \\
\text { Ref. }\end{array}$ \\
\hline \multicolumn{6}{|c|}{ Lectin-affinity mode } \\
\hline LC & Con A & $\begin{array}{l}\text { isoc. elu. } \\
50 \% \mathrm{ACN}, 2 \% \text { acetic acid }\end{array}$ & Enrichment of glycopeptides of trypsin digest of RNase B & $\begin{array}{l}\text { ESI-Ion trap - } \\
\text { MS/MS }\end{array}$ & $\begin{array}{l}2006 \\
{[98]}\end{array}$ \\
\hline LC & Con A & Me- $\alpha-D-M a n$ & Identification of glycoproteins from $20 \mu \mathrm{L}$ urine sample & ESI-MS & $\begin{array}{l}2009 \\
{[99]}\end{array}$ \\
\hline $\mathrm{LC}$ & ECL & Galactose & $\begin{array}{l}\text { Extraction of desialylated transferrin and desialylated } \\
\text { thryglobulin from a mixture of proteins (insulin chain B, } \\
\text { insulin, cyt } c \text {, bovine serum albumin, enolase and carbonic } \\
\text { anhydrase) } \\
\text { Extraction of spiked desialylated transferrin in E. coli cell lysate }\end{array}$ & UV Detector & $\begin{array}{l}2011 \\
{[100]}\end{array}$ \\
\hline $\begin{array}{l}\text { Manual (96 } \\
\text { well) }\end{array}$ & Con A & Me- $\alpha$-D-Man & Separation of Ova from BSA & MALDI-TOF & $\begin{array}{l}2012 \\
{[101]}\end{array}$ \\
\hline \multicolumn{6}{|c|}{ Boronic acid affinity mode } \\
\hline CEC & $-\mathrm{B}(\mathrm{OH})_{2}$ & $\begin{array}{l}\mathrm{pH} 8.5 \rightarrow \mathrm{pH} 2.7 \\
\mathrm{pH} 8.5 \rightarrow \mathrm{pH} 2.7\end{array}$ & $\begin{array}{l}\text { Specific capture of Ova from fresh egg white } \\
\text { Selective capture of glycoproteins Ovotransferrin (OVT) } \\
\text { and Ova from fresh egg white sample }\end{array}$ & $\begin{array}{l}\text { UV detector } \\
(214 \mathrm{~nm}) \\
\text { SDS-PAGE }\end{array}$ & $\begin{array}{l}2011 \\
{[102]}\end{array}$ \\
\hline CEC & $-\mathrm{B}(\mathrm{OH})_{2}$ & $\mathrm{pH} 8.5 \rightarrow \mathrm{pH} 2.7$ & $\begin{array}{l}\text { Capture of glycoproteins HRP and lactoferrin from a } \\
\text { mixture with non-glycosylated proteins BSA, lactoglobulin, } \\
\text { myoglobulin, and cyt } c\end{array}$ & $\begin{array}{l}\text { UV detector } \\
(214 \mathrm{~nm})\end{array}$ & $\begin{array}{l}2009 \\
{[103]}\end{array}$ \\
\hline LC & $-\mathrm{B}(\mathrm{OH})_{2}$ & $\begin{array}{l}\mathrm{pH} 10.0 \leftarrow \rightarrow \mathrm{pH} 7.4 \\
\mathrm{pH} 10.0 \leftarrow \rightarrow \mathrm{pH} 7.4\end{array}$ & $\begin{array}{l}\text { Extraction of sialylated glycoprotein human erythropoietin } \\
\text { (EPO) from a mixture with non-sialylated glycoprotein } \\
\text { HRP and non-glycoprotein BSA } \\
\text { Extraction of spiked sialylated glycoprotein EPO from a } \\
\text { human serum mixture with non-sialylated glycoprotein } \\
\text { RNase B }\end{array}$ & $\begin{array}{l}\text { MALDI-TOF- } \\
\text { MS }\end{array}$ & $\begin{array}{l}2013 \\
{[104]}\end{array}$ \\
\hline
\end{tabular}


Table 3. Cont.

\begin{tabular}{|c|c|c|c|c|c|}
\hline Type of Flow & $\begin{array}{l}\text { Functional } \\
\text { Ligand }\end{array}$ & $\begin{array}{l}\text { Elution Method } \\
\text { (isoc. elu. = isocratic elution; } \\
\text { grad. elu. = gradient elution) }\end{array}$ & Applications & $\begin{array}{l}\text { Detection } \\
\text { Method }\end{array}$ & $\begin{array}{c}\text { Year \& } \\
\text { Ref. }\end{array}$ \\
\hline \multicolumn{6}{|c|}{ Boronic acid affinity mode } \\
\hline CEC & $-\mathrm{B}(\mathrm{OH})_{2}$ & $\mathrm{pH} 8.0 \rightarrow \mathrm{pH} 3.6$ & $\begin{array}{l}\text { Selective capture of glycoproteins HRP, Ova from a } \\
\text { mixture with non-glycoproteins BSA, bovine hemoglobin } \\
(\mathrm{BHb}) \text {, cyt } c \text {, lysozyme and myoglobin } \\
\text { Selective capture of glycoproteins OVT and Ova from fresh } \\
\text { egg white sample }\end{array}$ & $\begin{array}{l}\text { UV detector } \\
(214 \mathrm{~nm})\end{array}$ & $\begin{array}{l}2011 \\
{[105]}\end{array}$ \\
\hline LC & $-\mathrm{B}(\mathrm{OH})_{2}$ & $\mathrm{pH} 7.2 \rightarrow 1 \%$ TFA & $\begin{array}{l}\text { Identification of glycoproteins Ova, OVT and Ovomucoid } \\
\text { (Ovo) }\end{array}$ & $\begin{array}{l}\text { MALDI-TOF- } \\
\text { MS }\end{array}$ & $\begin{array}{l}2013 \\
{[106]}\end{array}$ \\
\hline CEC & $-\mathrm{B}(\mathrm{OH})_{2}$ & $\begin{array}{l}\mathrm{pH} 7.4 \rightarrow \mathrm{pH} 2.7 \\
\mathrm{pH} 7.4 \rightarrow \mathrm{pH} 2.7\end{array}$ & $\begin{array}{l}\text { Selective capture of cis-diol containing glycoprotein RNase } \\
\text { B and Ova from a mixture with non cis-diol containing } \\
\text { glycoprotein RNase A at neutral } \mathrm{pH} \\
\text { 2D separation of HRP and 2D separation of lactoferrin } \\
\text { (showed 2 peaks) }\end{array}$ & $\begin{array}{l}\text { UV detector } \\
(214 \mathrm{~nm})\end{array}$ & $\begin{array}{l}2011 \\
{[107]}\end{array}$ \\
\hline CEC & $-\mathrm{B}(\mathrm{OH})_{2}$ & pH $8.5 \rightarrow \mathrm{pH} 2.7$ & $\begin{array}{l}\text { Separation of glycoproteins HRP, RNase B and lactoferrin } \\
\text { from a mixture with non-glycoproteins myoglobin and BSA }\end{array}$ & $\begin{array}{l}\text { UV detector } \\
(214 \mathrm{~nm})\end{array}$ & $\begin{array}{l}2013 \\
{[108]}\end{array}$ \\
\hline LC & $-\mathrm{B}(\mathrm{OH})_{2}$ & $\mathrm{pH} 7.0 \rightarrow \mathrm{pH} 2.7$ & $\begin{array}{l}\text { Specific capture of glycoproteins RNase B, HRP, anti-AFP } \\
\text { monoclonal antibody, anti-CEA polyclonal antibody, } \\
\text { anti-PSA monoclonal antibody, from a mixture with RNase } \\
\text { A, cyt } c \text { and } \beta \text {-lactoglobin (possible capture at pH } 5.0 \text { was } \\
\text { suggested) }\end{array}$ & $\begin{array}{l}\text { UV detector } \\
(214 \mathrm{~nm})\end{array}$ & $\begin{array}{l}2012 \\
{[109]}\end{array}$ \\
\hline $\begin{array}{l}\text { Manual } \\
\text { (syringe) }\end{array}$ & $-\mathrm{B}(\mathrm{OH})_{2}$ & pH $9.2 \rightarrow \mathrm{pH} 3.6$ & $\begin{array}{l}\text { Enrichment of glycopeptides in trypsin digest of HRP } \\
\text { Extraction of HRP from a mixture with non-glycosylated } \\
\text { BSA via polymer monolith microextraction (PMME) }\end{array}$ & $\begin{array}{l}\text { MALDI-TOF- } \\
\text { MS } \\
\text { SDS-PAGE }\end{array}$ & $\begin{array}{l}2009 \\
{[110]}\end{array}$ \\
\hline
\end{tabular}


Table 3. Cont.

\begin{tabular}{|c|c|c|c|c|c|}
\hline Type of Flow & $\begin{array}{l}\text { Functional } \\
\text { Ligand }\end{array}$ & $\begin{array}{l}\text { Elution Method } \\
\text { (isoc. elu. = isocratic elution; } \\
\text { grad. elu. = gradient elution) }\end{array}$ & Applications & $\begin{array}{l}\text { Detection } \\
\text { Method }\end{array}$ & $\begin{array}{l}\text { Year \& } \\
\text { Ref. }\end{array}$ \\
\hline \multicolumn{6}{|c|}{ Boronic acid affinity mode } \\
\hline $\mathrm{LC}$ & $-\mathrm{B}(\mathrm{OH})_{2}$ & $\mathrm{pH} 8.5 \rightarrow 0.2 \mathrm{M} \mathrm{HAc}$ & $\begin{array}{l}\text { Selective capture of glycoproteins HRP and transferrin from } \\
\text { a mixture with non-glycoproteins BSA and cyt } c\end{array}$ & $\begin{array}{l}\text { UV detector } \\
(278 \mathrm{~nm})\end{array}$ & $\begin{array}{l}2011 \\
{[111]}\end{array}$ \\
\hline $\mathrm{CEC}$ & $-\mathrm{B}(\mathrm{OH})_{2}$ & $\mathrm{pH} 8.6 \rightarrow \mathrm{pH} 3.6$ & $\begin{array}{l}\text { Selective extraction of HRP and enrichment of human } \\
\text { serum that contains human serum albumin, IgG, transferrin } \\
\text { and spiked HRP }\end{array}$ & $\begin{array}{l}\text { UV detector } \\
(214 \mathrm{~nm}) \\
\text { SDS-PAGE }\end{array}$ & $\begin{array}{l}2013 \\
{[112]}\end{array}$ \\
\hline LC & $-\mathrm{B}(\mathrm{OH})_{2}$ & $\mathrm{pH} 7.0 \rightarrow 0.2 \mathrm{M} \mathrm{HAc}$ & $\begin{array}{l}\text { Selective capture of glycoproteins Ova and OVT from fresh } \\
\text { egg white }\end{array}$ & $\begin{array}{l}\text { UV detector } \\
(214 \mathrm{~nm}) \\
\text { SDS-PAGE }\end{array}$ & $\begin{array}{l}2013 \\
{[113]}\end{array}$ \\
\hline $\mathrm{LC} / \mathrm{CE}$ & $-\mathrm{B}(\mathrm{OH})_{2}$ & $\mathrm{pH} 7.0 \rightarrow \mathrm{pH} 2.7$ & Rapid selection of HRP-binding DNA aptamers & $\begin{array}{l}\text { UV detector } \\
(214 \mathrm{~nm}) \\
\text { CE-LIF }\end{array}$ & $\begin{array}{l}2013 \\
{[114]}\end{array}$ \\
\hline CEC & $-\mathrm{B}(\mathrm{OH})_{2}$ & $\mathrm{pH} 7.0 \rightarrow \mathrm{pH} 2.7$ & $\begin{array}{l}\text { Potential alternative to Protein A in affinity } \\
\text { chromatography of glycan-containing antibodies }\end{array}$ & $\begin{array}{l}\text { UV detector } \\
\text { MALDI-TOF- } \\
\text { MS }\end{array}$ & $\begin{array}{l}2012 \\
{[116]}\end{array}$ \\
\hline \multicolumn{6}{|c|}{ Protein A affinity mode } \\
\hline $\mathrm{CE}$ & Protein A & $\mathrm{pH} 7.2 \rightarrow \mathrm{pH} 2.3$ & Rapid separation of $\mathrm{hIgG}$ in human serum & $\begin{array}{l}\text { UV detector } \\
(239 \mathrm{~nm})\end{array}$ & $\begin{array}{l}2002 \\
{[115]}\end{array}$ \\
\hline
\end{tabular}


Table 3. Cont.

\begin{tabular}{|c|c|c|c|c|c|}
\hline Type of Flow & $\begin{array}{l}\text { Functional } \\
\text { Ligand }\end{array}$ & $\begin{array}{l}\text { Elution Method } \\
\text { (isoc. elu. = isocratic elution; } \\
\text { grad. elu. = gradient elution) }\end{array}$ & Applications & $\begin{array}{l}\text { Detection } \\
\text { Method }\end{array}$ & $\begin{array}{l}\text { Year \& } \\
\text { Ref. }\end{array}$ \\
\hline \multicolumn{6}{|l|}{ Mixed mode } \\
\hline \multirow[t]{2}{*}{$\begin{array}{l}\text { Nano-LC } \\
\text { CEC }\end{array}$} & $\begin{array}{l}\text { (1) Lectin } \\
\text { affinity } \\
\text { (a) WGA } \\
\text { (b) Con A }\end{array}$ & $\begin{array}{l}\text { (1a) isoc. elu. GlcNAc } \\
\text { (1b) isoc. elu. Methyl- } \alpha-D- \\
\text { mannopyranoside }\end{array}$ & $\begin{array}{l}\text { (1a) Capture of glycoproteins AGP and k-Casein } \\
\text { (1b) Capture of glycoproteins Ova and transferrin }\end{array}$ & $\begin{array}{l}\text { UV detector } \\
(280 \mathrm{~nm})\end{array}$ & $\begin{array}{l}2009 \\
{[117]}\end{array}$ \\
\hline & $\begin{array}{l}\text { (2) Polar } \\
(\mathrm{OH}-)\end{array}$ & $\begin{array}{l}\text { (2) isoc. elu. } 75 \% \mathrm{ACN} \text { with } \\
\text { small amount of modifiers } \\
\beta-\mathrm{CD}\end{array}$ & $\begin{array}{l}\text { (2) Polar }(\mathrm{CN}-\mathrm{OH}) \text { based separation of } \mathrm{N} \text {-glycans derived } \\
\text { from AGP and Ova }\end{array}$ & & \\
\hline LC & $\begin{array}{l}\text { (1) Hydroph } \\
\text { obic } \\
\text { Alkyl chain } \\
\text { and benzene } \\
\text { rings } \\
\text { (2) Cationic } \\
\text { exchange } \\
\text { Negatively } \\
\text { charged } \\
\text { boronic } \\
\text { acid at high } \\
\text { pH }\end{array}$ & $\begin{array}{l}\text { grad. elu. } \\
\text { Increasing ACN content } \\
(20 \%-40 \%) \text { in mobile phase } \\
\text { with counter-ion } \\
\text { (trifluoroacetate anions, } \\
\text { TFA) }\end{array}$ & $\begin{array}{l}\text { Separation of iron-binding glycoprotein transferrin from a } \\
\text { mixture with non-glycoproteins cyt } c \text { and myoglobin }\end{array}$ & $\begin{array}{l}\text { UV detector } \\
(214 \mathrm{~nm})\end{array}$ & $\begin{array}{l}2013 \\
{[118]}\end{array}$ \\
\hline
\end{tabular}




\subsubsection{Boronate Affinity}

Lectin-affinity separation is a highly selective method but appears primarily limited to $\mathrm{N}$ - and O-linked glycoproteins [187]. C-mannosylation at tryptophan, more recently discovered, has been found not to be recognized by mannose-binding lectins [188]. Lectin affinity columns do appear to bind phosphoglycosylated protein [11]. Polar/HILIC approach, on the other hand, may capture those very hydrophilic non-glycan peptides in the sample, therefore providing a less effective separation [189]. Another approach that is getting huge attention recently is the affinity separation using boronic acids. Boronic acids form stronger covalent bonds rather than non-covalent interactions with cis-diol-containing molecules such as RNA, nucleosides, glycans, glycoproteins and glycopeptides. The binding is reversible and $\mathrm{pH}$-dependent, i.e., it forms five or six-membered cyclic esters in basic conditions and dissociates when the conditions are switched to acidic. Acids such as formic acid and acetic acid are commonly used as the eluting mobile phase. Boronic acids as ligands are found in applications such as sensing, separation and self-assembly. The use of boronate functionalized monolithic stationary phases in separation of cis-diol containing molecules has been reviewed [190,191]. Boronate affinity will not be specific to glycans or glycoproteins and will bind other cis-diol containing molecules in a sample. If a boronate affinity column has hydrophobic character, then reversed phase non-specific interactions can degrade the performance [192]. Standard boronate affinity methods usually require the use of $\mathrm{pH}>8-9$ for capture (above the $\mathrm{pK}_{\mathrm{a}}$ of the boronic acid), and this may degrade certain targets. However, sialic acids are known to bind strongly to boronic acid at $\mathrm{pH}<\mathrm{pK}_{\mathrm{a}}$ of the boronic acid. Recent efforts have focused on lowering the $\mathrm{pH}$ required for glycan capture using modified boronic acids and different binding modes [193].

The first developed boronate affinity polymeric monolithic capillary column in separation of cis-diol containing molecules was tested to separate catechol from quinol at $\mathrm{pH} 8.5$ [191]. Boronate affinity monolithic columns were initially characterized as having a hydrophobic phase that limits the selectivity of the column and therefore required addition of organic solvent ACN to suppress the hydrophobic effect. A hydrophobic phenylboronate affinity monolithic capillary column was prepared and used to specifically capture glycoprotein at $\mathrm{pH}$ 8.5. The separation using this monolithic column was optimized by varying the ratio of porogenic solvents, monomers ratio, ACN content and buffer concentration. Buffer concentration was controlled to suppress the electrostatic interactions between negatively charged monomer VPBA and proteins. The application was extended to extraction of glycoproteins from fresh egg white samples using in-tube solid-phase microextraction (SPME) eluting with acetate buffer at pH 2.7 [102]. Organic solvents, as mentioned above, may cause denaturation of proteins and could lead to precipitation and clogging of the column. Therefore, a report used a hydrophilic cross-linker $N, N^{\prime}$-methylenebisacrylamide (MBAA) to prepare a hydrophilic boronate monolithic capillary. The hydrophilicity of the monolith reduced the hydrophobic interactions that could retain non-glycoproteins and interfered with the separation of glycoproteins. Using this monolith, addition of organic solvent was limited [103]. Likewise, a hydrophilic boronate monolithic affinity column was developed for selectively extracting sialylated glycoproteins versus non-sialylated glycoproteins through $\mathrm{pH}$ manipulation. When the $\mathrm{pH}$ is less than the boronic acid's $\mathrm{pK}_{\mathrm{a}}$ by one $\mathrm{pH}$ unit or more, for example at physiological $\mathrm{pH}$, the column preferentially captured sialylated glycoproteins (e.g., recombinant human erythropoietin, EPO). Otherwise, non-sialylated HRP was captured at basic pH (10.0) [104]. Sialic acids was shown to bind 
common boronic acids when $\mathrm{pH}$ is lower than the $\mathrm{pKa}$ value of the boronic acid [194]. Another approach was the preparation of an organic-inorganic hybrid affinity monolithic column via one-pot synthesis. At $\mathrm{pH}$ 8.0, high selectivity was achieved, represented by the big difference in binding capacity between glycoprotein Ova and non-glycoprotein BSA as compared to same binding capacity when at acidic media [105]. In another work, a completely inorganic borated titania monolith prepared via sol-gel process, and packed in a syringe was used in selective extraction of glycoproteins from fresh egg white [106].

Through the established principle, boronic acid chromatography (BAC)-based techniques are required to operate at high $\mathrm{pH}$. However, the highly alkaline environment could lead to degradation of labile compounds and could also cause interference. In response to this, a new approach to preparing boronate-functionalized polymeric monoliths was proposed via ring-opening polymerization with synergistic co-monomers. Through this approach, great selectivity was achieved under neutral conditions [195]. The approach was exemplified by the work that prepared a boronic acid functionalized monolithic capillary by in situ free radical polymerization of 4-(3-butenylsulfonyl) phenyl-boronic acid (BSPBA) as functional monomer. BSPA has a lower $\mathrm{pK}_{\mathrm{a}}$ value of 7.0 that enables stronger affinity at neutral $\mathrm{pH}$ and reduces the hydrophobicity of the column. This monolith was applied in selective capture of glycoproteins from human serum at physiological condition of $\mathrm{pH}$ 7.4. However, because BSPBA is a strong hydrogen acceptor, there was suspected secondary H-bonding [107]. An improved selectivity was achieved when a monolithic capillary was prepared using hydrophilic functional monomer 3-aminophenylboronic acid (APBA, $\mathrm{pK}_{\mathrm{a}}=8.2$ ) and hydrophilic cross-linker $N, N$ '-methylenebisacrylamide (MBAA). The reverse-phase (hydrophobic) retention was completely suppressed. The monolith favors the affinity at physiological $\mathrm{pH}$. The prepared monolithic column was characterized to have the highest density of accessible boronic acid (due to longer spacer arm of APBA) [108]. Glycoprotein separation at acidic $\mathrm{pH}$ of 5.0 was reported in another work using benzoboroxoles, a unique class of boronic acids with excellent water solubility and improved sugar-binding capacity [109].

There are various non-conventional ways of preparation of boronate affinity monolithic columns that have been reported. A monolithic capillary $(530 \mu \mathrm{m}$ i.d.) was prepared by a one-step in situ polymerization with functional monomer 3-acrylamidophenylboronic acid to produce boronic acid affinity based column. This monolithic column was used to replace the metallic needle of the pinhead of a syringe and was used as sorbent for polymer monolith microextraction (PMME). The monolithic capillary sorbent was used to enrich glycopeptides of tryptic HRP digests for MALDI-TOF MS analysis. The desorption solvent used was $100 \mathrm{mM}$ phosphate buffer at $\mathrm{pH} 3.6$ [110]. In another work, metal-organic gels (MOGs) were used as porogenic templates in the polymerization to form the monolithic column. The column was used to analyze biological sample, i.e., capturing large proteins in a rapid and efficient way. MOGs are stable and simple to prepare and been used as an alternative method to form macroporous materials [196]. Pore size was controlled by adjusting the reaction temperature during the preparation [111]. One work used the technology of molecularly imprinting to prepare a HRP-imprinted monolithic column. This was done by a sequence of steps: (1) a VPBA-based polymeric monolith was prepared; (2) glycoprotein horseradish peroxidase (HRP) was immobilized on the surface of the monolith at $\mathrm{pH}$ 8.6; (3) self-polymerization of dopamine (DA) on the surface; and (4) washing off the reversibly immobilized HRP at $\mathrm{pH}$ 3.6. Afterwards, HRP-specific recognition cavities were created and used to selectively enrich HRP in a $10 \mu \mathrm{L}$ sample of human serum. The selectivity of cavities formed in the column was suggested as due to the environment that is complementary to the shape, size, and functional 
groups of HRP [112]. In other work, a click chemistry modification was applied via $\mathrm{Cu}(\mathrm{I})$-catalyzed 1,3-dipolar azide-alkyne cycloaddition (CuAAC) reaction to immobilize azide-boronate ligand into a parent azide-functionalized hybrid monolithic column. The post-modification via click chemistry under mild condition ( $\mathrm{pH}$ 7.5) was applicable in organic, aqueous and biological environments with high compatibility and stability with no side of side-reactions [197]. The near-neutral optimum binding capacity of the boronate affinity material was observed due to the lower $\mathrm{pK}_{\mathrm{a}}$ of the boronic acid ligand used. The developed monolith was then tested and was able to selectively capture glycoproteins in a fresh egg white sample in a $\mathrm{pH}$ 7.5 0.1 M phosphate buffer medium [113].

The application of boronate affinity monolithic capillary column was extended to enrichment of glycoprotein-binding aptamer via systematic evolution of ligands by exponential enrichment (SELEX). SELEX is a method of isolating target-binding single stranded DNA (ssDNA) from the random pool [198]. The advantage of this method over conventional SELEX is that it is economical requiring only $10-20 \mu \mathrm{L}$ of target and library DNA per cycle [114]. A monolithic capillary column with covalently immobilized protein A was used to determine the hIgG concentration in human serum [115]. Protein A is an expensive protein. In one work, a boronate affinity monolithic column was proposed to be an inexpensive and stable alternative to protein A in specific capture and isolation of antibodies. Monoliths were prepared by ring-opening polymerization with synergistic monomers that produce a bimodal porous (macropores and mesopores) structure. This exhibited steric hindrance to selectively capture a large glycan-containing antibody such as hIgG. The separation was based on the combined size-exclusion and boronate affinity. The binding capacity of the monolith was found to be comparable to a number of protein A mimics. The monolith was able to isolate antibodies from smaller proteins human serum albumin and transferrin in serum sample. Furthermore, when the monoclonal antibody anti-EPO was immobilized, it was able to capture EPO showing the oriented binding capability of the monolith that can be useful in immune assays [116].

\subsubsection{Mixed-Mode}

Mixed mode monolithic columns offer great advantages such as providing interactive stationary phases and utilization of less material in fabrication. However the optimization of separation is challenging because of the uncertainty as to which mode is playing the dominant role in the separation. A monolithic column with readily reactive functionality for further modification to produce different modes for separation is likely to be useful in glycomics. This is due to the fact that after the separations and enrichment of glycoproteins and glycopeptides, subsequent separation and enrichment of glycans is required after deglycosylation. One work prepared a silica-based monolithic column that had readily reactive $\gamma$-glycidoxypropyltrimethoxysilane functionality at the surface for further modifications. It was utilized to immobilize lectins (Con A and WGA) to provide a lectin affinity mode for LC separation of glycoproteins and also modification with $1 H$-imidazole-4,5-dicarbonitrile to provide polar cyano-mode for CEC separation. Both modes of separation were optimized and tested for their respective separation functions [117].

A monolithic column with a mixed mode of cationic exchange and hydrophobic with boronic acid functionality is likely to offer better performance of separation of cis-diol containing molecules like glycans and glycoproteins. The monolithic column was prepared without further modification by incorporating the required functional monomers in a co-polymerization mixture (lauryl methacrylate, 
LMA = hydrophobic and 4-vinylphenylboronic acid, VPBA = boronic acid). The ionizable boronic acid functional group creates the cationic exchange mode. An iron-binding glycoprotein TRF showed increasing retention time as the ACN content of the mobile phase was increased. Increasing the ACN content decreases the hydrophobic interactions between the solute and hydrophobic surface [118].

\subsection{Multidimensional Systems}

Multidimensional systems are the recent application of developing monolithic column materials in separation and analysis of glycans. Several methods are done in series via flow-porous monolithic columns that are linked together in series for more efficient separations. Due to unique hydrodynamic properties of monolithic columns that provide faster separations, overlapping of those least retained compounds in one dimension and most retained and being eluted in the next dimension can be avoided. Multidimensional systems can be either coupled on-line or off-line, and there are advantages and disadvantages to each approach [199]. On-line coupled multidimensional separation and analysis provides the enhanced selectivity of a multidimensional system together with the advantage of automation and a shorter overall analysis time [200]. Loss of samples is minimal [201] in an on-line system since reinjection is not required and good reproducibility [202] can be achieved with less risk of sample contamination. On-line systems generally require a more complex setup and may not allow for full optimization of the conditions for each mode of separation. On-line systems may be preferred when the amount of sample is limited. Off-line coupled methods, on the other hand, make use of less complex systems and have minimal void volume [203]. Retention times in an on-line system may be longer due to the more complex setup that may include valve modules or trap columns through which the sample must pass [204]. However, with an off-line system the analysis time can also be long due to sample preparation steps required between each mode of separation. Analysis time must be compared on a case by case basis. Compatibility of monolithic preparative columns to analytical instruments such as MS may provide a small-scale solid platform or phases in developing multidimensional automated set-up for analysis of glycans for "nano-glycomics". Monolithic columns showed potential to be part of the electrospray emitter that is used to integrate nano-LC and CEC to nanoelectrospray MS. The usual problems in coupled system such as dead volume at the end of the column and clogging by buffer components can be reduced or avoided when a monolithic column are used (Table 4).

A 2-dimensional separation system of coupled lectin monolithic columns (LCA column and WGA columns) were set-up and used in nano-LC and CEC separation of glycoproteins. The set-up showed more enhanced separation using CEC mode than in LC mode. The combined nano-LC and CEC separation using a series of WGA $\rightarrow$ LCA monoliths was done in 4 steps: (1) nano-LC loading of glycoprotein mixtures; (2) nano-LC washing with GlcNAc (hapten for LCA) then with Me- $\alpha$-D-Man (hapten for WGA); (3) CEC separation in WGA monolith; and (4) CEC separation in LCA monolith. The set-up was able to separate six intact glycoproteins in $35 \mathrm{~min}$ (Figure 6). Those glycoproteins that have complementary glycan structure with LCA, i.e., fucosylated core region of bi- and triantennary complex type N-glycans, were eluted first; followed by those glycoproteins specific to WGA, i.e., with sialic acids. Since AGP is a highly glycosylated protein with five N-glycosylation site, which are bi-, tri-, and tetraantennary complex-type $\mathrm{N}$-glycans with some fucose residues and sialylated [205], it was captured by both WGA and LCA lectins [119]. 
Table 4. Multi-dimensional systems that used monolithic columns in simultaneous, rapid and efficient deglycosylation, separation and analysis of glycans, glycopeptides, and glycoproteins.

\begin{tabular}{|c|c|c|c|c|}
\hline D & Components & Applications & Detection & Ref. \\
\hline $\begin{array}{l}\text { On-line } \\
\text { 2D }\end{array}$ & $\begin{array}{l}\text { (1) LCA affinity } \\
\text { column } \\
\text { (2) WGA affinity } \\
\text { column }\end{array}$ & $\begin{array}{l}\text { Nano-LC and CEC separation of } \\
\text { glycoproteins AGP, fetuin, } \kappa \text {-Casein, avidin, } \\
\text { holotransferrin, and collagen }\end{array}$ & $\begin{array}{l}\text { UV-detector } \\
(280 \mathrm{~nm})\end{array}$ & $\begin{array}{l}2005 \\
{[119]}\end{array}$ \\
\hline $\begin{array}{l}\text { On-line } \\
\text { 2D }\end{array}$ & $\begin{array}{l}\text { (1) Con A affinity } \\
\text { column } \\
\text { (2) RP column }\end{array}$ & $\begin{array}{l}\text { Nano-LC separation of glycoproteins glucose } \\
\text { oxidase, human transferrin and OVT from a } \\
\text { mixture with non-glycoproteins trypsinogen } \\
\text { and } \alpha \text {-lactalbumin }\end{array}$ & $\begin{array}{l}\text { UV- detector } \\
(210 \mathrm{~nm})\end{array}$ & $\begin{array}{l}2005 \\
{[120]}\end{array}$ \\
\hline $\begin{array}{l}\text { On-line } \\
\text { 3D }\end{array}$ & $\begin{array}{l}\text { (1) WGA affinity } \\
\text { column } \\
\text { (2) Con A affinity } \\
\text { column } \\
\text { (3) RCI-I affinity } \\
\text { column }\end{array}$ & $\begin{array}{l}\text { Capture and profiling breast cancer and } \\
\text { disease-free sera glycoproteins }\end{array}$ & LC-MS/MS & $\begin{array}{l}2012 \\
{[121]}\end{array}$ \\
\hline $\begin{array}{l}\text { Off- } \\
\text { line } \\
2 \mathrm{D}\end{array}$ & $\begin{array}{l}\text { (1) RP column } \\
\text { (2) ZIC-HILIC } \\
\text { column }\end{array}$ & $\begin{array}{l}\text { Enrichment of glycopeptides using batch } \\
\text { HILIC } \\
\text { Enhanced separation for profiling and } \\
\text { detection of glycopeptides }\end{array}$ & ESI-MS/MS & $\begin{array}{l}2010 \\
{[122]} \\
{[122]}\end{array}$ \\
\hline $\begin{array}{l}\text { On-line } \\
\text { and } \\
\text { off-line } \\
\text { 2D }\end{array}$ & $\begin{array}{l}\text { (1) PNGase F } \\
\text { reactor column } \\
\text { (2) HILIC column }\end{array}$ & $\begin{array}{l}\text { Fast and robust analysis of N-glycans from } \\
\text { glycoproteins by integrated deglycosylation } \\
\text { and enrichment }\end{array}$ & $\begin{array}{l}\text { MALDI-TOF- } \\
\text { MS }\end{array}$ & $\begin{array}{l}2013 \\
{[83]}\end{array}$ \\
\hline $\begin{array}{l}\text { On-line } \\
\text { 2D }\end{array}$ & $\begin{array}{l}\text { (1) PNGase F } \\
\text { reactor column } \\
\text { (2) Porous graphitic } \\
\text { carbon (PGC) HPLC } \\
\text { chip }\end{array}$ & $\begin{array}{l}\text { Online simultaneous release, sample } \\
\text { preparation, LC separation and MS analysis of } \\
\text { both neutral and acidic N-glycans in just few } \\
\text { minutes }\end{array}$ & LC-MS/MS & $\begin{array}{l}2012 \\
{[84]}\end{array}$ \\
\hline $\begin{array}{l}\text { Off- } \\
\text { line } \\
2 \mathrm{D}\end{array}$ & $\begin{array}{l}\text { (1) RP18e column } \\
\text { (2) HILIC column }\end{array}$ & $\begin{array}{l}\text { Glycoproteomic reactor (integrated } \\
\text { purification/ desalting, trypsin digestion, } \\
\text { enrichment and deglycosylation) }\end{array}$ & $\begin{array}{l}\text { MALDI-TOF- } \\
\text { MS }\end{array}$ & $\begin{array}{l}2013 \\
{[123]}\end{array}$ \\
\hline
\end{tabular}

A two-dimensional separation scheme composed of lectin (Con A) affinity column in the first dimension and a reversed-phase (RP) column on the second dimension was designed and used for separation of glycoconjugates by nano-liquid chromatography. The simultaneous separation was done by two grouped steps: (1) separation by Con A affinity column until the uncaptured proteins reached the RP column, disconnecting the column and then gradient elution in RP column by increasing \% ACN content in mobile phase; (2) the two columns were reconnected, eluted by the hapten sugar, and upon reaching the RP column using the same gradient elution in the RP column [120]. 


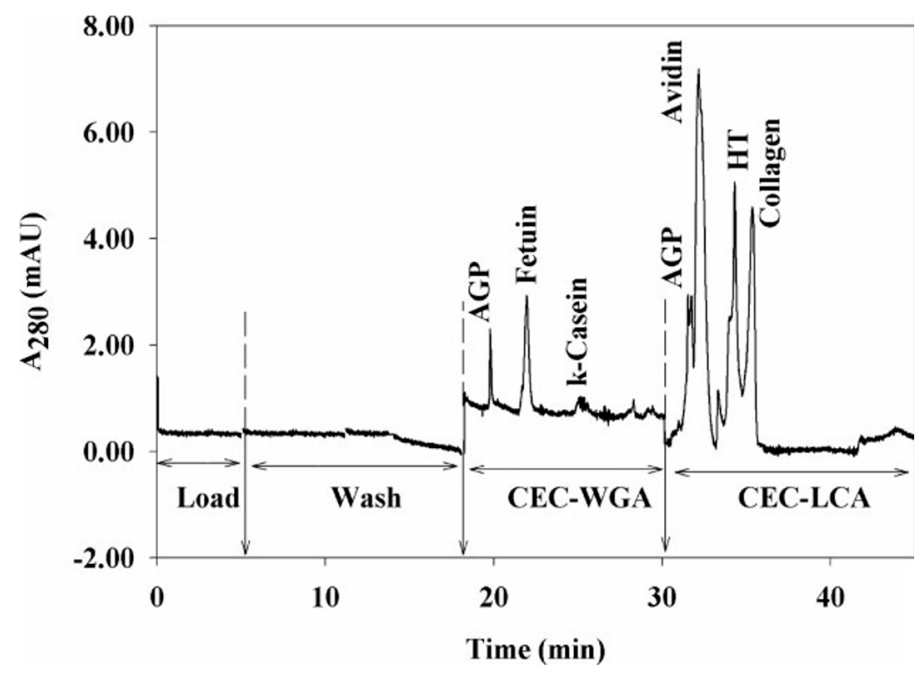

Figure 6. Electrochromatogram of six glycoproteins separated through nano-liquid chromatography (LC) and CEC using tandem wheat germ agglutinin (WGA) $\rightarrow$ Lens culinaris agglutinin (LCA) affinity columns. Reprinted with permission from reference [119].

A three-dimensional system consisted of three lectin affinity mode monolithic columns was designed and used for the capturing and profiling breast cancer and disease-free sera. The sequence WCR (1st:WGA, 2nd:Con A, 3rd:RCA-I) captured the highest number of glycoproteins from the sera with the least number of redundant captured proteins. The analysis was done by LC-MS/MS. Using this threedimensional set-up, 23 candidate biomarkers for breast cancer were obtained through MS spectral counts data [121]. In another work, a comprehensive separation using two-dimensional set-up consisted of RP and ZIC-HILIC monolithic columns were designed and integrated with ESI-MS and ESI-MS/MS analysis. RP and ZIC-HILIC modes of separations have complementary functions: RP can separate glycopeptides based on peptide sequence and degree of sialylation while ZIC-HILIC can separate glycan based on difference on structure (polarity) with appropriate mobile phase composition. Chromatograms were able to identify the glycosylation sites (GS) of glycans in AGP after batch HILIC enrichment, MS analysis and database search (Figure 7). GS were located in regions that became accessible after addition of endoproteinase Glu-C, and not identified when only trypsin was used [122].

A complete set-up that can do deglycosylation to enrichment prior to the analysis was demonstrated in two studies. The PNGase F microreactor was integrated with HILIC column then coupled to ESI-MS detection system to have a multidimensional deglycosylation system of glycans and analysis on its intact form [83]. Similarly, a multidimensional deglycosylation system consisting of PNGase F monolithic microreactor, C8 trap and a porous graphitic carbon (PGC) HPLC-chip was interfaced to an ion trap MS for similar purpose [84]. A two-dimensional RP-HILIC system was used for an off-line glycoproteomic reactor that integrated protein purification/desalting, trypsin digestion, enrichment, and deglycosylation of N-glycosylated peptides. The whole process took only three hours. The microreactor was sensitive and allowed detection of four out nine $\mathrm{N}$-glycosylation sites of $2.5 \mathrm{fmol}$ HRP versus only one detected by in-solution digestion. The detection of glycans and peptides were done using LC-MS/MS and MALDI-TOF-MS, respectively. The microreactor was able to map 486 unique N-glycosylation sites by using only $1 \mu \mathrm{g}$ protein sample extracted from $\sim 10^{4} \mathrm{HeLa}$ cells [123]. 

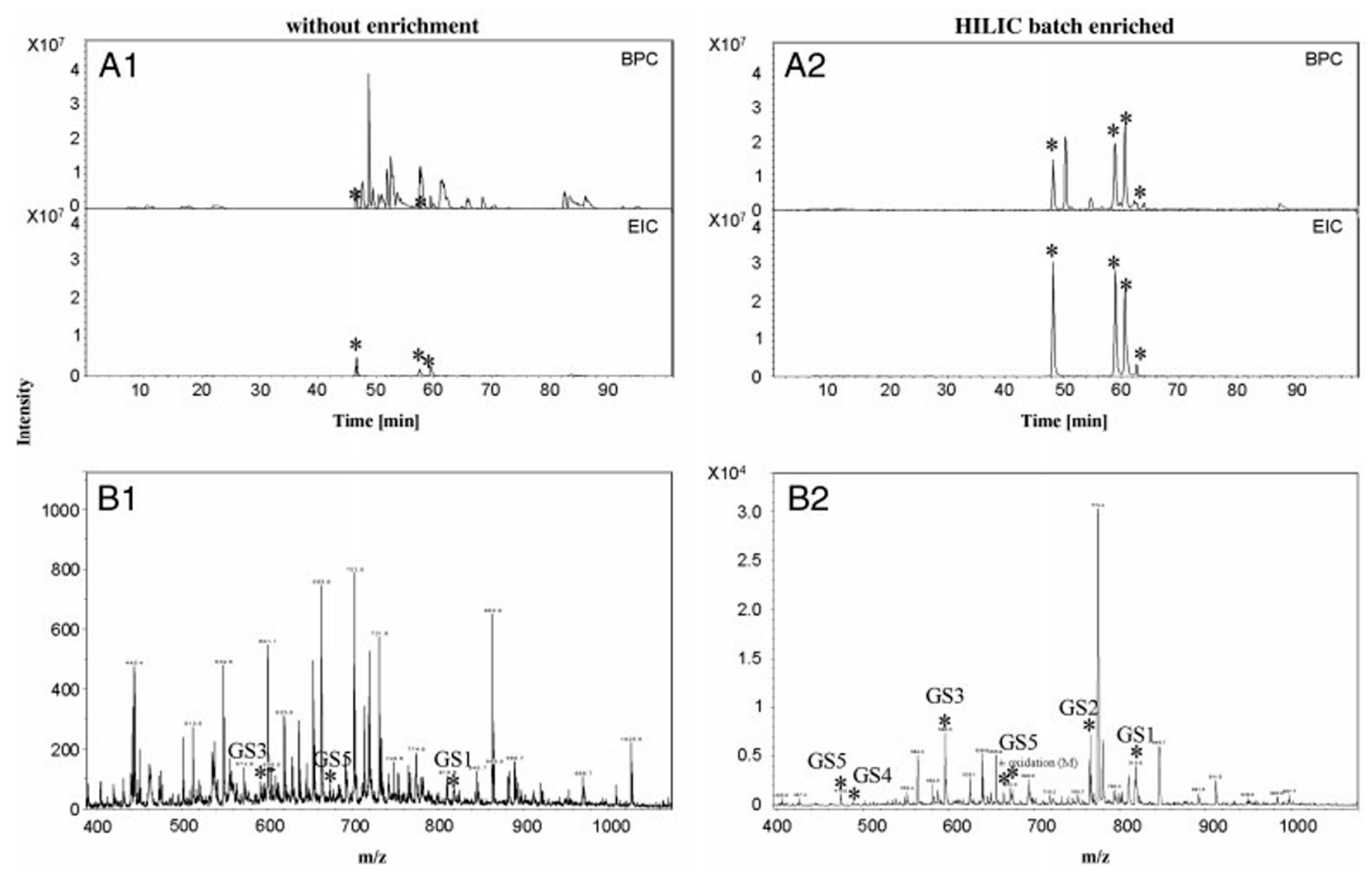

Figure 7. Chromatograms of efficient glycopeptides enrichment. LC (RP18e)/electrospray ionization (ESI)-MS analysis of trypsin digest of antibody IgG1 without enrichment (A1) and with HILIC enrichment (A2). Upper figure: base peak chromatogram. Lower figure: extracted ion chromatograms (EICs) of selected glycopeptides $(\mathrm{m} / \mathrm{z} 1318.3,1339.4,1226.9$, $1280.9,1334.8,1402.6,1329.2,1383.2,1383.2,1431.9)$. LC (RP18e)/ESI-MS/MS analysis of N-glycosidase F digest of $\alpha 1$-acid glycoprotein (trypsin and Glu-C digested) without enrichment (B1) and with HILIC enrichment (B2). Glycopeptides ( $m / z$ 474.8, 488.8, 596.4, $664.5,672.4,765.6,817.1)$ with their corresponding glycosylation site (GS)* were identified by Mascot database search. Reprinted with permission from reference [122].

\section{Conclusion}

Glycans, along with proteins, nucleic acids and lipids, complete the big four macromolecules in life. Relative to the other three, structural characterization of glycans is more challenging. Detailed knowledge in site-specific glycosylation of proteins, through glycomics, will be a big contribution to the development of post-genomic projects. The research works summarized here showed their respective responses to the current approach in glycomics that is to develop more efficient and faster methods of separation and analysis of glycans. The great characteristics of monolithic materials described above (1) easy in situ preparation; (2) versatility for surface modifications; and (3) high permeability, faster and efficient separations were utilized to prepare monolithic reaction and separation columns that can help to resolve the complexities of glycan structures. In situ preparation allowed developing monolithic columns in smaller scale such as capillaries and microfluidic channels that increased the limit of detection (LOD) of the analysis. Analysis of very small amounts of samples became possible at lowest concentration of attomol level. Microreactor columns can load enzymes such as trypsin and PNGase F with high capacity and density. These provide faster, efficient and economical use of these enzymes in digestion and glycan release. Monolithic capillaries are suitable to couple to MS instruments, for 
example as nanospray emitters of ESI-MS that uses ion trap. Monomers and functional compounds are available and can be added during or after the polymerization of monoliths, that produced monolithic columns with desired morphology, structure and functionality such as various modes of separation that make monolithic columns versatile tools in glycomics. Using monolithic columns, multi-dimensional systems that integrate glycan release, separation, enrichment and analysis were developed toward automated, miniaturized and high-throughput glycomics.

\section{Acknowledgments}

The second author acknowledges Professor Alexei Demchenko for inspiring his interest in glycoscience. Support of our current collaborative research from the NIH is acknowledged (NIGMS award R01-GM111835).

\section{Author Contributions}

The first author prepared the initial draft, which was edited and refined by the second author and then both authors contributed equally to revision and completion of the manuscript.

\section{Conflicts of Interest}

The authors declare no conflict of interest.

\section{References}

1. Varki, A. Biological roles of oligosaccharides: All of the theories are correct. Glycobiology 1993, 3, 97-130.

2. Pfaunmiller, E.L.; Paulemond, M.L.; Dupper, C.M.; Hage, D.S. Affinity monolith chromatography: A review of principles and recent analytical applications. Anal. Bioanal. Chem. 2013, 405, 2133-2145.

3. Walsh, Z.; Paull, B.; Macka, M. Inorganic monoliths in separation science: A review. Anal. Chim. Acta 2012, 750, 28-47.

4. Vlakh, E.G.; Tennikova, T.B. Applications of polymethacrylate-based monoliths in high-performance liquid chromatography. J. Chromatogr. A 2009, 1216, 2637-2650.

5. Potter, O.G.; Hilder, E.F. Porous polymer monoliths for extraction: Diverse applications and platforms. J. Sep. Sci. 2008, 31, 1881-1906.

6. Zou, H.; Huang, X.; Ye, M.; Luo, Q. Monolithic stationary phases for liquid chromatography and capillary electrochromatography. J. Chromatogr. A 2002, 954, 5-32.

7. Tanaka, N.; Kobayashi, H.; Nakanishi, K.; Minakuchi, H.; Ishizuka, N. Monolithic LC columns. Anal. Chem. 2001, 73, 420a-429a.

8. Saunders, K.C.; Ghanem, A.; Boon Hon, W.; Hilder, E.F.; Haddad, P.R. Separation and sample pre-treatment in bioanalysis using monolithic phases: A review. Anal. Chim. Acta 2009, 652, $22-31$. 
9. Hofsteenge, J.; Muller, D.R.; de Beer, T.; Loffler, A.; Richter, W.J.; Vliegenthart, J.F. New type of linkage between a carbohydrate and a protein: C-Glycosylation of a specific tryptophan residue in human RNase Us. Biochemistry 1994, 33, 13524-13530.

10. Gonzalez de Peredo, A.; Klein, D.; Macek, B.; Hess, D.; Peter-Katalinic, J.; Hofsteenge, J. C-Mannosylation and o-fucosylation of thrombospondin type 1 repeats. Mol. Cell. Proteomics 2002, 1, 11-18.

11. Haynes, P.A. Phosphoglycosylation: A new structural class of glycosylation? Glycobiology 1998, $8,1-5$.

12. Fasel, N.; Rousseaux, M.; Schaerer, E.; Medof, M.E.; Tykocinski, M.L.; Bron, C. In vitro attachment of glycosyl-inositolphospholipid anchor structures to mouse Thy-1 antigen and human decay-accelerating factor. Proc. Natl. Acad. Sci. USA 1989, 86, 6858-6862.

13. Rasmussen, J.R.; Davis, J.; Risley, J.M.; Van Etten, R.L. Identification and derivatization of (oligosaccharyl)amines obtained by treatment of asparagine-linked glycopeptides with N-GLYCANASE enzyme. J. Am. Chem. Soc. 1992, 114, 1124-1126.

14. Patel, T.; Bruce, J.; Merry, A.; Bigge, C.; Wormald, M.; Parekh, R.; Jaques, A. Use of hydrazine to release in intact and unreduced form both $\mathrm{N}$ - and O-linked oligosaccharides from glycoproteins. Biochemistry 1993, 32, 679-693.

15. Huang, Y.; Mechref, Y.; Novotny, M.V. Microscale nonreductive release of O-linked glycans for subsequent analysis through MALDI mass spectrometry and capillary electrophoresis. Anal. Chem. 2001, 73, 6063-6069.

16. Mechref, Y.; Hu, Y.; Garcia, A.; Hussein, A. Identifying cancer biomarkers by mass spectrometrybased glycomics. Electrophoresis 2012, 33, 1755-1767.

17. Dey, S. Single nucleotide polymorphisms in human P-glycoprotein: Its impact on drug delivery and disposition. Expert Opin. Drug Deliver. 2006, 3, 23-35.

18. Greer, D.A.; Ivey, S. Distinct N-glycan glycosylation of P-glycoprotein isolated from the human uterine sarcoma cell line MES-SA/Dx5. Biochim. Biophys. Acta 2007, 1770, 1275-1282.

19. Gribar, J.J.; Ramachandra, M.; Hrycyna, C.A.; Dey, S.; Ambudkar, S.V. Functional characterization of glycosylation-deficient human P-glycoprotein using a vaccinia virus expression system. J. Membr. Biol. 2000, 173, 203-214.

20. Wanebo, H.J.; Rao, B.; Pinsky, C.M.; Hoffman, R.G.; Stearns, M.; Schwartz, M.K.; Oettgen, H.F. Preoperative carcinoembryonic antigen level as a prognostic indicator in colorectal cancer. N. Engl. J. Med. 1978, 299, 448-451.

21. Thompson, I.M.; Pauler, D.K.; Goodman, P.J.; Tangen, C.M.; Lucia, M.S.; Parnes, H.L.; Minasian, L.M.; Ford, L.G.; Lippman, S.M.; Crawford, E.D.; et al. Prevalence of prostate cancer among Men with a prostate-specific antigen level $\leq 4.0 \mathrm{ng}$ per milliliter. N. Engl. J. Med. 2004, 350, 2239-2246.

22. Dwek, R.A. Glycobiology: Toward understanding the function of sugars. Chem. Rev. 1996, 96, 683-720.

23. Takahashi, N. Three-dimensional mapping of N-linked oligosaccharides using anion-exchange, hydrophobic and hydrophilic interaction modes of high-performance liquid chromatography. J. Chromatogr. A 1996, 720, 217-225.

24. Hirabayashi, J.; Hashidate, T.; Kasai, K. Glyco-catch method: A lectin affinity technique for glycoproteomics. J. Biomol. Tech. 2002, 13, 205-218. 
25. Woosley, B.; Xie, M.; Wells, L.; Orlando, R.; Garrison, D.; King, D.; Bergmann, C. Comprehensive glycan analysis of recombinant Aspergillus niger endo-polygalacturonase C. Anal. Biochem. 2006, 354, 43-53.

26. Ruhaak, L.R.; Zauner, G.; Huhn, C.; Bruggink, C.; Deelder, A.M.; Wuhrer, M. Glycan labeling strategies and their use in identification and quantification. Anal. Bioanal. Chem. 2010, 397, 3457-3481.

27. El Rassi, Z. Recent developments in capillary electrophoresis and capillary electrochromatography of carbohydrate species. Electrophoresis 1999, 20, 3134-3144.

28. Liu, Y.; Shu, C.; Lamb, J.D. High-performance capillary electrophoretic separation of carbohydrates with indirect UV detection using diethylamine and borate as electrolyte additives. J. Capillary Electrophor. 1997, 4, 97-103.

29. Voegel, P.D.; Zhou, W.; Baldwin, R.P. Integrated capillary electrophoresis/electrochemical detection with metal film electrodes directly deposited onto the capillary tip. Anal. Chem. 1997, 69, 951-957.

30. Pilobello, K.T.; Mahal, L.K. Lectin microarrays for glycoprotein analysis. Method. Mol. Biol. 2007, 385, 193-203.

31. Chen, S.; Haab, B.B. Analysis of glycans on serum proteins using antibody microarrays. Method. Mol. Biol. 2009, 520, 39-58.

32. Chen, S.; LaRoche, T.; Hamelinck, D.; Bergsma, D.; Brenner, D.; Simeone, D.; Brand, R.E.; Haab, B.B. Multiplexed analysis of glycan variation on native proteins captured by antibody microarrays. Nat. Methods 2007, 4, 437-444.

33. Roth, Z.; Yehezkel, G.; Khalaila, I. Identification and quantification of protein glycosylation. Int. J. Carbohydr. Chem. 2012, 2012, Article ID 640923.

34. Duus, J.Ø.; Gotfredsen, C.H.; Bock, K. Carbohydrate structural determination by NMR spectroscopy: Modern methods and limitations. Chem. Rev. 2000, 100, 4589-4614.

35. Fellenberg, M.; Behnken, H.N.; Nagel, T.; Wiegandt, A.; Baerenfaenger, M.; Meyer, B. Glycan analysis: Scope and limitations of different techniques - A case for integrated use of LC-MS(/MS) and NMR techniques. Anal. Bioanal. Chem. 2013, 405, 7291-7305.

36. Toukach, F.V.; Ananikov, V.P. Recent advances in computational predictions of NMR parameters for the structure elucidation of carbohydrates: Methods and limitations. Chem. Soc. Rev. 2013, 42, 8376-8415.

37. Wormald, M.R.; Petrescu, A.J.; Pao, Y.L.; Glithero, A.; Elliott, T.; Dwek, R.A. Conformational studies of oligosaccharides and glycopeptides: Complementarity of NMR, X-ray crystallography, and molecular modelling. Chem. Rev. 2002, 102, 371-386.

38. Geyer, H.; Geyer, R. Strategies for analysis of glycoprotein glycosylation. Biochim. Biophys. Acta 2006, 1764, 1853-1869.

39. Zaia, J. Mass Spectrometry and the emerging field of glycomics. Chem. Biol. 2008, 15, 881-892.

40. Mechref, Y.; Novotny, M.V. Structural investigations of glycoconjugates at high sensitivity. Chem. Rev. 2002, 102, 321-369.

41. Wuhrer, M. Glycomics using mass spectrometry. Glycoconjug. J. 2013, 30, 11-22.

42. Krauss, M.; Singer, H.; Hollender, J. LC-high resolution MS in environmental analysis: From target screening to the identification of unknowns. Anal. Bioanal. Chem. 2010, 397, 943-951. 
43. Bereman, M.S.; Lyndon, M.M.; Dixon, R.B.; Muddiman, D.C. Mass measurement accuracy comparisons between a double-focusing magnetic sector and a time-of-flight mass analyzer. Rapid Commun. Mass Spectrom. 2008, 22, 1563-1566.

44. Perry, R.H.; Cooks, R.G.; Noll, R.J. Orbitrap mass spectrometry: Instrumentation, ion motion and applications. Mass Spectrom. Rev. 2008, 27, 661-699.

45. March, R.E. An Introduction to quadrupole ion trap mass spectrometry. J. Mass Spectrom. 1997, 32, 351-369.

46. Krutchinsky, A.N.; Kalkum, M.; Chait, B.T. Automatic identification of proteins with a MALDIquadrupole ion trap mass spectrometer. Anal. Chem. 2001, 73, 5066-5077.

47. Trauger, S.A.; Webb, W.; Siuzdak, G. Peptide and protein analysis with mass spectrometry. Spectroscopy 2002, 16, 15-28.

48. Boesl, U.; Weinkauf, R.; Schlag, E.W. Reflectron time-of-flight mass spectrometry and laser excitation for the analysis of neutrals, ionized molecules and secondary fragments. Int. J. Mass Spectrom. 1992, 112, 121-166.

49. Atwood, J.A.; Cheng, L.; Alvarez-Manilla, G.; Warren, N.L.; York, W.S.; Orlando, R. Quantitation by isobaric labeling: Applications to glycomics. J. Proteome Res. 2007, 7, 367-374.

50. Hopfgartner, G.; Varesio, E.; Tschappat, V.; Grivet, C.; Bourgogne, E.; Leuthold, L.A. Triple quadrupole linear ion trap mass spectrometer for the analysis of small molecules and macromolecules. J. Mass Spectrom. 2004, 39, 845-855.

51. Want, E.J.; Cravatt, B.F.; Siuzdak, G. The expanding role of mass spectrometry in metabolite profiling and characterization. ChemBioChem 2005, 6, 1941-1951.

52. Griffin, T.J.; Xie, H.; Bandhakavi, S.; Popko, J.; Mohan, A.; Carlis, J.V.; Higgins, L. iTRAQ reagent-based quantitative proteomic analysis on a linear ion trap mass spectrometer. J. Proteome Res. 2007, 6, 4200-4209.

53. Pabst, M.; Bondili, J.S.; Stadlmann, J.; Mach, L.; Altmann, F. Mass + retention time = structure: A strategy for the analysis of N-glycans by carbon LC-ESI-MS and its application to fibrin N-glycans. Anal. Chem. 2007, 79, 5051-5057.

54. Harvey, D.J. Analysis of carbohydrates and glycoconjugates by matrix-assisted laser desorption/ionization mass spectrometry: An update for 2009-2010. Mass Spectrom. Rev. 2014, doi: $10.1002 /$ mas.21411.

55. Harvey, D.J. Identification of protein-bound carbohydrates by mass spectrometry. Proteomics 2001, 1, 311-328.

56. Wuhrer, M.; Deelder, A.M. Negative-mode MALDI-TOF/TOF-MS of oligosaccharides labeled with 2-aminobenzamide. Anal. Chem. 2005, 77, 6954-6959.

57. Mechref, Y.; Kang, P.; Novotny, M.V. Differentiating structural isomers of sialylated glycans by matrix-assisted laser desorption/ionization time-of-flight/time-of-flight tandem mass spectrometry. Rapid Commun. Mass Spectrom. 2006, 20, 1381-1389.

58. Wuhrer, M.; Catalina, M.I.; Deelder, A.M.; Hokke, C.H. Glycoproteomics based on tandem mass spectrometry of glycopeptides. J. Chromatogr. B 2007, 849, 115-128.

59. Prien, J.M.; Ashline, D.J.; Lapadula, A.J.; Zhang, H.; Reinhold, V.N. The high mannose glycans from bovine ribonuclease B isomer characterization by ion trap MS. J. Am. Soc. Mass Spectrom. 2009, 20, 539-556. 
60. An, H.J.; Lebrilla, C.B. Structure elucidation of native N- and O-linked glycans by tandem mass spectrometry (tutorial). Mass Spectrom. Rev. 2011, 30, 560-578.

61. Li, B.; An, H.J.; Hedrick, J.L.; Lebrilla, C.B. Collision-induced dissociation tandem mass spectrometry for structural elucidation of glycans. Method. Mol. Biol. 2009, 534, 133-145.

62. Jonscher, K.R.; Yates, J.R., 3rd. The quadrupole ion trap mass spectrometer-A small solution to a big challenge. Anal. Biochem. 1997, 244, 1-15.

63. Scigelova, M.; Hornshaw, M.; Giannakopulos, A.; Makarov, A. Fourier transform mass spectrometry. Mol. Cell. Proteomics 2011, 10, doi: 10.1074/mcp.M111.009431.

64. Bahr, U.; Pfenninger, A.; Karas, M.; Stahl, B. High-sensitivity analysis of neutral underivatized oligosaccharides by nanoelectrospray mass spectrometry. Anal. Chem. 1997, 69, 4530-4535.

65. Alley, W.R., Jr.; Mechref, Y.; Novotny, M.V. Use of activated graphitized carbon chips for liquid chromatography/mass spectrometric and tandem mass spectrometric analysis of tryptic glycopeptides. Rapid Commun. Mass Spectrom. 2009, 23, 495-505.

66. Zaia, J. Mass spectrometry and the emerging field of glycomics. Chem. Biol. 2008, 15, 881-892.

67. Leymarie, N.; Zaia, J. Effective use of mass spectrometry for glycan and glycopeptide structural analysis. Anal. Chem. 2012, 84, 3040-3048.

68. Lazar, I.M.; Lazar, A.C.; Cortes, D.F.; Kabulski, J.L. Recent advances in the MS analysis of glycoproteins: Theoretical considerations. Electrophoresis 2011, 32, 3-13.

69. Wuhrer, M. Glycomics using mass spectrometry. Glycoconjug. J. 2013, 30, 11-22.

70. Cortes, D.F.; Kabulski, J.L.; Lazar, A.C.; Lazar, I.M. Recent advances in the MS analysis of glycoproteins: Capillary and microfluidic workflows. Electrophoresis 2011, 32, 14-29.

71. Pabst, M.; Altmann, F. Glycan analysis by modern instrumental methods. Proteomics 2011, 11, 631-643.

72. Ye, X.; Luke, B.; Andresson, T.; Blonder, J. $18 \mathrm{O}$ stable isotope labeling in MS-based proteomics. Brief. Funct. Genomic. Proteomic. 2009, 8, 136-144.

73. Kaji, H.; Saito, H.; Yamauchi, Y.; Shinkawa, T.; Taoka, M.; Hirabayashi, J.; Kasai, K.; Takahashi, $\mathrm{N}$.; Isobe, T. Lectin affinity capture, isotope-coded tagging and mass spectrometry to identify N-linked glycoproteins. Nat. Biotechnol. 2003, 21, 667-672.

74. Palmisano, G.; Melo-Braga, M.N.; Engholm-Keller, K.; Parker, B.L.; Larsen, M.R. Chemical deamidation: A common pitfall in large-scale N-linked glycoproteomic mass spectrometry-based analyses. J. Proteome Res. 2012, 11, 1949-1957.

75. Hao, P.; Ren, Y.; Alpert, A.J.; Sze, S.K. Detection, evaluation and minimization of nonenzymatic deamidation in proteomic sample preparation. Mol. Cell. Proteomics 2011, 10, doi: 10.1074/mcp.O111.009381.

76. Angel, P.M.; Lim, J.M.; Wells, L.; Bergmann, C.; Orlando, R. A potential pitfall in 18O-based N-linked glycosylation site mapping. Rapid Commun. Mass Spectrom. 2007, 21, 674-682.

77. Wuhrer, M.; Deelder, A.M.; Hokke, C.H. Protein glycosylation analysis by liquid chromatography-mass spectrometry. J. Chromatogr. B 2005, 825, 124-133.

78. Mechref, Y. Analysis of glycans derived from glycoconjugates by capillary electrophoresis-mass spectrometry. Electrophoresis 2011, 32, 3467-3481. 
79. Tennikova, T.B.; Bleha, M.; Švec, F.; Almazova, T.V.; Belenkii, B.G. High-performance membrane chromatography of proteins, a novel method of protein separation. J. Chromatogr. A 1991, 555, 97-107.

80. Svec, F.; Frechet, J.M.J. Continuous rods of macroporous polymer as high-performance liquid chromatography separation media. Anal. Chem. 1992, 64, 820-822.

81. Hjertén, S.; Liao, J.-L.; Zhang, R. High-performance liquid chromatography on continuous polymer beds. J. Chromatogr. A 1989, 473, 273-275.

82. Krenkova, J.; Lacher, N.A.; Svec, F. Highly efficient enzyme reactors containing trypsin and endoproteinase LysC immobilized on porous polymer monolith coupled to MS suitable for analysis of antibodies. Anal. Chem. 2009, 81, 2004-2012.

83. Krenkova, J.; Lacher, N.A.; Svec, F. Multidimensional system enabling deglycosylation of proteins using a capillary reactor with peptide-N-glycosidase $\mathrm{F}$ immobilized on a porous polymer monolith and hydrophilic interaction liquid chromatography-mass spectrometry of glycans. J. Chromatogr. A 2009, 1216, 3252-3259.

84. Jmeian, Y.; Hammad, L.A.; Mechref, Y. Fast and efficient online release of N-glycans from glycoproteins facilitating liquid chromatography-tandem mass spectrometry glycomic profiling. Anal. Chem. 2012, 84, 8790-8796.

85. Palm, A.K.; Novotny, M.V. A monolithic PNGase F enzyme microreactor enabling glycan mass mapping of glycoproteins by mass spectrometry. Rapid Commun. Mass Spectrom. 2005, 19, 1730-1738.

86. Krenkova, J.; Szekrenyes, A.; Keresztessy, Z.; Foret, F.; Guttman, A. Oriented immobilization of peptide-N-glycosidase $\mathrm{F}$ on a monolithic support for glycosylation analysis. J. Chromatogr. A 2013, 1322, 54-61.

87. Palm, A.; Novotny, M.V. Macroporous Polyacrylamide/Poly(ethylene glycol) Matrixes as Stationary Phases in Capillary Electrochromatography. Anal. Chem. 1997, 69, 4499-4507.

88. Allen, D.; El Rassi, Z. Capillary electrochromatography with monolithic silica columns III. Preparation of hydrophilic silica monoliths having surface-bound cyano groups: Chromatographic characterization and application to the separation of carbohydrates, nucleosides, nucleic acid bases and other neutral polar species. J. Chromatogr. A 2004, 1029, 239-247.

89. Zhong, H.; El Rassi, Z. Neutral polar methacrylate-based monoliths for normal phase nano-LC and CEC of polar species including N-glycans. J. Sep. Sci. 2009, 32, 10-20.

90. Guryča, V.; Mechref, Y.; Palm, A.K.; Michálek, J.; Pacáková, V.; Novotný, M.V. Porous polyacrylamide monoliths in hydrophilic interaction capillary electrochromatography of oligosaccharides. J. Biochem. Biophys. Method. 2007, 70, 3-13.

91. Ikegami, T.; Horie, K.; Saad, N.; Hosoya, K.; Fiehn, O.; Tanaka, N. Highly efficient analysis of underivatized carbohydrates using monolithic-silica-based capillary hydrophilic interaction (HILIC) HPLC. Anal. Bioanal. Chem. 2008, 391, 2533-2542.

92. Que, A.H.; Novotny, M.V. Separation of neutral saccharide mixtures with capillary electrochromatography using hydrophilic monolithic columns. Anal. Chem. 2002, 74, 5184-5191.

93. Que, A.H.; Novotny, M.V. Structural characterization of neutral oligosaccharide mixtures through a combination of capillary electrochromatography and ion trap tandem mass spectrometry. Anal. Bioanal. Chem. 2003, 375, 599-608. 
94. Que, A.H.; Mechref, Y.; Huang, Y.; Taraszka, J.A.; Clemmer, D.E.; Novotny, M.V. Coupling capillary electrochromatography with electrospray Fourier transform mass spectrometry for characterizing complex oligosaccharide pools. Anal. Chem. 2003, 75, 1684-1690.

95. Liu, H.-Y.; Yang, G.-L.; Bai, L.-G.; Feng, X.-J.; Yang, G.-Q.U.N. Separation of immunoglobulin $\mathrm{G}$ and immunoglobulin $\mathrm{Y}$ on poly(vinyl ester resin-co-ethylene dimethacrylate) monolith. Chin. J. Anal. Chem. 2009, 37, 325-329.

96. Liu, J.; Ren, L.; Liu, Y.; Li, H.; Liu, Z. Weak anion exchange chromatographic profiling of glycoprotein isoforms on a polymer monolithic capillary. J. Chromatogr. A 2012, 1228, 276-282.

97. Hilder, E.F.; Svec, F.; Fréchet, J.M.J. Latex-functionalized monolithic columns for the separation of carbohydrates by micro anion-exchange chromatography. J. Chromatogr. A 2004, 1053, 101-106.

98. Bedair, M.; Oleschuk, R.D. Lectin affinity chromatography using porous polymer monolith assisted nanoelectrospray MS/MS. Analyst 2006, 131, 1316-1321.

99. Feng, S.; Yang, N.; Pennathur, S.; Goodison, S.; Lubman, D.M. Enrichment of glycoproteins using nanoscale chelating concanavalin a monolithic capillary chromatography. Anal. Chem. 2009, 81, 3776-3783.

100. Alwael, H.; Connolly, D.; Clarke, P.; Thompson, R.; Twamley, B.; O'Connor, B.; Paull, B. Pipettetip selective extraction of glycoproteins with lectin modified gold nano-particles on a polymer monolithic phase. Analyst 2011, 136, 2619-2628.

101. Reichelt, S.; Elsner, C.; Prager, A.; Naumov, S.; Kuballa, J.; Buchmeiser, M.R. Aminofunctionalized monolithic spin-type columns for high-throughput lectin affinity chromatography of glycoproteins. Analyst 2012, 137, 2600-2607.

102. Lin, Z.A.; Pang, J.L.; Lin, Y.; Huang, H.; Cai, Z.W.; Zhang, L.; Chen, G.N. Preparation and evaluation of a phenylboronate affinity monolith for selective capture of glycoproteins by capillary liquid chromatography. Analyst 2011, 136, 3281-3288.

103. Ren, L.; Liu, Y.; Dong, M.; Liu, Z. Synthesis of hydrophilic boronate affinity monolithic capillary for specific capture of glycoproteins by capillary liquid chromatography. J. Chromatogr. A 2009, $1216,8421-8425$.

104. Lu, Y.; Bie, Z.; Liu, Y.; Liu, Z. Fine-tuning the specificity of boronate affinity monoliths toward glycoproteins through $\mathrm{pH}$ manipulation. Analyst 2013, 138, 290-298.

105. Lin, Z.; Pang, J.; Yang, H.; Cai, Z.; Zhang, L.; Chen, G. One-pot synthesis of an organic-inorganic hybrid affinity monolithic column for specific capture of glycoproteins. Chem. Commun. (Camb) 2011, 47, 9675-9677.

106. Wang, S.T.; Chen, D.; Ding, J.; Yuan, B.F.; Feng, Y.Q. Borated titania, a new option for the selective enrichment of cis-diol biomolecules. Chemistry 2013, 19, 606-612.

107. Liu, Y.; Ren, L.; Liu, Z. A unique boronic acid functionalized monolithic capillary for specific capture, separation and immobilization of cis-diol biomolecules. Chem. Commun. (Camb) 2011, 47, 5067-5069.

108. Wang, X.; Liu, Y.; Ren, L.; Li, H.; Liu, Z. Development of poly((3-acrylamidophenyl)boronic acid-co-N,N-methylenebisacrylamide) monolithic capillary for the selective capture of cis-diol biomolecules. Anal. Method. 2013, 5, 5444-5449. 
109. Li, H.; Wang, H.; Liu, Y.; Liu, Z. A benzoboroxole-functionalized monolithic column for the selective enrichment and separation of cis-diol containing biomolecules. Chem. Commun. (Camb) 2012, 48, 4115-4117.

110. Chen, M.; Lu, Y.; Ma, Q.; Guo, L.; Feng, Y.Q. Boronate affinity monolith for highly selective enrichment of glycopeptides and glycoproteins. Analyst 2009, 134, 2158-2164.

111. Yang, F.; Lin, Z.; He, X.; Chen, L.; Zhang, Y. Synthesis and application of a macroporous boronate affinity monolithic column using a metal-organic gel as a porogenic template for the specific capture of glycoproteins. J. Chromatogr. A 2011, 1218, 9194-9201.

112. Lin, Z.; Wang, J.; Tan, X.; Sun, L.; Yu, R.; Yang, H.; Chen, G. Preparation of boronatefunctionalized molecularly imprinted monolithic column with polydopamine coating for glycoprotein recognition and enrichment. J. Chromatogr. A 2013, 1319, 141-147.

113. Yang, F.; Mao, J.; He, X.W.; Chen, L.X.; Zhang, Y.K. Preparation of a boronate-functionalized affinity hybrid monolith for specific capture of glycoproteins. Anal. Bioanal. Chem. 2013, 405, 5321-5331.

114. Nie, H.; Chen, Y.; Lu, C.; Liu, Z. Efficient selection of glycoprotein-binding DNA aptamers via boronate affinity monolithic capillary. Anal. Chem. 2013, 85, 8277-8283.

115. Pan, Z.; Zou, H.; Mo, W.; Huang, X.; Wu, R. Protein A immobilized monolithic capillary column for affinity chromatography. Anal. Chim. Acta 2002, 466, 141-150.

116. Liu, Y.; Lu, Y.; Liu, Z. Restricted access boronate affinity porous monolith as a protein A mimetic for the specific capture of immunoglobulin G. Chem. Sci. 2012, 3, 1467-1471.

117. Zhong, H.; El Rassi, Z. Monolithic silica capillary columns having immobilized lectins and surface bound polar functionalities for lectin affinity and normal phase nano-LC and CEC of glycoconjugates, respectively. J. Sep. Sci. 2009, 32, 1642-1653.

118. Aydoğan, C.; Yılmaz, F.; Denizli, A. Cation exchange/hydrophobic interaction monolithic chromatography of small molecules and proteins by nano liquid chromatography. J. Sep. Sci. 2013, 36, 1685-1692.

119. Okanda, F.M.; El Rassi, Z. Affinity monolithic capillary columns for glycomics/proteomics: 1. Polymethacrylate monoliths with immobilized lectins for glycoprotein separation by affinity capillary electrochromatography and affinity nano-liquid chromatography in either a single column or columns coupled in series. Electrophoresis 2006, 27, 1020-1030.

120. Bedair, M.; El Rassi, Z. Affinity chromatography with monolithic capillary columns. II. Polymethacrylate monoliths with immobilized lectins for the separation of glycoconjugates by nano-liquid affinity chromatography. J. Chromatogr. A 2005, 1079, 236-245.

121. Selvaraju, S.; E1 Rassi, Z. Tandem lectin affinity chromatography monolithic columns with surface immobilised concanavalin A, wheat germ agglutinin and Ricinus communis agglutinin-I for capturing sub-glycoproteomics from breast cancer and disease-free human sera. J. Sep. Sci. 2012, $35,1785-1795$.

122. Wohlgemuth, J.; Karas, M.; Jiang, W.; Hendriks, R.; Andrecht, S. Enhanced glyco-profiling by specific glycopeptide enrichment and complementary monolithic nano-LC (ZICHILIC/RP18e)/ESI-MS analysis. J. Sep. Sci. 2010, 33, 880-890. 
123. Liu, J.; Wang, F.; Lin, H.; Zhu, J.; Bian, Y.; Cheng, K.; Zou, H. Monolithic capillary column based glycoproteomic reactor for high-sensitive analysis of N-glycoproteome. Anal. Chem. 2013, 85, 2847-2852.

124. Madera, M.; Mechref, Y.; Klouckova, I.; Novotny, M.V. Semiautomated high-sensitivity profiling of human blood serum glycoproteins through lectin preconcentration and multidimensional chromatography/tandem mass spectrometry. J. Proteome Res. 2006, 5, 2348-2363.

125. Hjerten, S. "Molecular sieve" chromatography on polyacrylamide gels, prepared according to a simplified method. Arch. Biochem. Biophys. 1962, Suppl 1, 147-151.

126. Minakuchi, H.; Nakanishi, K.; Soga, N.; Ishizuka, N.; Tanaka, N. Octadecylsilylated porous silica rods as separation media for reversed-phase liquid chromatography. Anal. Chem. 1996, 68, 3498-3501.

127. Kato, M.; Sakai-Kato, K.; Toyo'oka, T. Silica sol-gel monolithic materials and their use in a variety of applications. J. Sep. Sci. 2005, 28, 1893-1908.

128. Ma, J.; Liang, Z.; Qiao, X.; Deng, Q.; Tao, D.; Zhang, L.; Zhang, Y. Organic-inorganic hybrid silica monolith based immobilized trypsin reactor with high enzymatic activity. Anal. Chem. 2008, 80, 2949-2956.

129. Wu, M.; Wu, R.; Wang, F.; Ren, L.; Dong, J.; Liu, Z.; Zou, H. "One-pot" process for fabrication of organic-silica hybrid monolithic capillary columns using organic monomer and alkoxysilane. Anal. Chem. 2009, 81, 3529-3536.

130. Liang, C.; Dai, S.; Guiochon, G. A graphitized-carbon monolithic column. Anal. Chem. 2003, 75, 4904-4912.

131. Tan, Y.H.; Fujikawa, K.; Pornsuriyasak, P.; Alla, A.J.; Ganesh, N.V.; Demchenko, A.V.; Stine, K.J. Lectin-carbohydrate interactions on nanoporous gold monoliths. New J. Chem. 2013, 37, 2150-2165.

132. Tan, Y.H.; Schallom, J.R.; Ganesh, N.V.; Fujikawa, K.; Demchenko, A.V.; Stine, K.J. Characterization of protein immobilization on nanoporous gold using atomic force microscopy and scanning electron microscopy. Nanoscale 2011, 3, 3395-3407.

133. Sklenářová, H.; Chocholouš, P.; Koblová, P.; Zahálka, L.; Šatínský, D.; Matysová, L.; Solich, P. High-resolution monolithic columns-A new tool for effective and quick separation. Anal. Bioanal. Chem. 2013, 405, 2255-2263.

134. Fekete, S.; Veuthey, J.-L.; Eeltink, S.; Guillarme, D. Comparative study of recent wide-pore materials of different stationary phase morphology, applied for the reversed-phase analysis of recombinant monoclonal antibodies. Anal. Bioanal. Chem. 2013, 405, 3137-3151.

135. Namera, A.; Nakamoto, A.; Saito, T.; Miyazaki, S. Monolith as a new sample preparation material: Recent devices and applications. J. Sep. Sci. 2011, 34, 901-924.

136. Vlakh, E.G.; Tennikova, T.B. Preparation of methacrylate monoliths. J. Sep. Sci. 2007, 30, 2801-2813.

137. Sherrington, D.C. Preparation, structure and morphology of polymer supports. Chem. Commun. 1998, 2275-2286.

138. Rieux, L.; Niederländer, H.; Verpoorte, E.; Bischoff, R. Silica monolithic columns: Synthesis, characterisation and applications to the analysis of biological molecules. J. Sep. Sci. 2005, 28, $1628-1641$.

139. Arrua, R.D.; Alvarez Igarzabal, C.I. Macroporous monolithic supports for affinity chromatography. J. Sep. Sci. 2011, 34, 1974-1987. 
140. Eeltink, S.; Svec, F. Recent advances in the control of morphology and surface chemistry of porous polymer-based monolithic stationary phases and their application in CEC. Electrophoresis 2007, 28, 137-147.

141. Svec, F.; Frechet, J.M. New designs of macroporous polymers and supports: From separation to biocatalysis. Science 1996, 273, 205-211.

142. Duan, J.; Sun, L.; Liang, Z.; Zhang, J.; Wang, H.; Zhang, L.; Zhang, W.; Zhang, Y. Rapid protein digestion and identification using monolithic enzymatic microreactor coupled with nano-liquid chromatography-electrospray ionization mass spectrometry. J. Chromatogr. A 2006, 1106, 165-174.

143. Ma, J.; Liang, Z.; Qiao, X.; Deng, Q.; Tao, D.; Zhang, L.; Zhang, Y. Organic-inorganic hybrid silica monolith based immobilized trypsin reactor with high enzymatic activity. Anal. Chem. 2008, 80, 2949-2956.

144. Lin, Z.; Huang, H.; Sun, X.; Lin, Y.; Zhang, L.; Chen, G. Monolithic column based on a poly(glycidyl methacrylate-co-4-vinylphenylboronic acid-co-ethylene dimethacrylate) copolymer for capillary liquid chromatography of small molecules and proteins. J. Chromatogr. A 2012, 1246, 90-97.

145. Levkin, P.A.; Eeltink, S.; Stratton, T.R.; Brennen, R.; Robotti, K.; Yin, H.; Killeen, K.; Svec, F.; Fréchet, J.M.J. Monolithic porous polymer stationary phases in polyimide chips for the fast high-performance liquid chromatography separation of proteins and peptides. J. Chromatogr. A 2008, 1200, 55-61.

146. Bandari, R.; Kuballa, J.; Buchmeiser, M.R. Ring-opening metathesis polymerization-derived, lectin-functionalized monolithic supports for affinity separation of glycoproteins. J. Sep. Sci. 2013, 36, 1169-1175.

147. Bedair, M.; El Rassi, Z. Affinity chromatography with monolithic capillary columns: I. Polymethacrylate monoliths with immobilized mannan for the separation of mannose-binding proteins by capillary electrochromatography and nano-scale liquid chromatography. J. Chromatogr. A 2004, 1044, 177-186.

148. Ericson, C.; Holm, J.; Ericson, T.; Hjertén, S. Electroosmosis- and pressure-driven chromatography in chips using continuous beds. Anal. Chem. 1999, 72, 81-87.

149. Wu, R.; Hu, L.; Wang, F.; Ye, M.; Zou, H. Recent development of monolithic stationary phases with emphasis on microscale chromatographic separation. J. Chromatogr. A 2008, 1184, 369-392.

150. Sondergeld, L.J.; Bush, M.E.; Bellinger, A.; Bushey, M.M. Butyl acrylate porous polymer monoliths in fused-silica capillaries for use in capillary electrochromatography. J. Chromatogr. A 2003, 1004, 155-165.

151. Chirica, G.S.; Remcho, V.T. A simple procedure for the preparation of fritless columns by entrapping conventional high performance liquid chromatography sorbents. Electrophoresis 2000, 21, 3093-3101.

152. Fujimoto, C. Recent developments in column technology for fritless packed column Chromatography 2001, 22, 145-150.

153. Bragg, W.; Shamsi, S.A. Development of a fritless packed column for capillary electrochromatography-mass spectrometry. J. Chromatogr. A 2011, 1218, 8691-8700.

154. Hahn, R.; Jungbauer, A. Peak broadening in protein chromatography with monoliths at very fast separations. Anal. Chem. 2000, 72, 4853-4858. 
155. Bailey, U.M.; Schulz, B.L. Deglycosylation systematically improves N-glycoprotein identification in liquid chromatography-tandem mass spectrometry proteomics for analysis of cell wall stress responses in Saccharomyces cerevisiae lacking Alg3p. J. Chromatogr. B 2013, 923-924, 16-21.

156. Tarentino, A.L.; Gomez, C.M.; Plummer, T.H. Deglycosylation of asparagine-linked glycans by peptide:N-glycosidase F. Biochemistry 1985, 24, 4665-4671.

157. Tretter, V.; Altmann, F.; Marz, L. Peptide-N4-(N-acetyl-beta-glucosaminyl)asparagine amidase F cannot release glycans with fucose attached alpha 1----3 to the asparagine-linked N-acetylglucosamine residue. Eur. J. Biochem. 1991, 199, 647-652.

158. Cingoz, A.; Hugon-Chapuis, F.; Pichon, V. Total on-line analysis of a target protein from plasma by immunoextraction, digestion and liquid chromatography-mass spectrometry. J. Chromatogr. B 2010, 878, 213-221.

159. Bruyneel, B.; Hoos, J.S.; Smoluch, M.T.; Lingeman, H.; Niessen, W.M.; Irth, H. Trace analysis of proteins using postseparation solution-phase digestion and electrospray mass spectrometric detection of marker peptides. Anal. Chem. 2007, 79, 1591-1598.

160. Kuster, B.; Naven, T.J.; Harvey, D.J. Rapid approach for sequencing neutral oligosaccharides by exoglycosidase digestion and matrix-assisted laser desorption/ionization time-of-flight mass spectrometry. J. Mass Spectrom. 1996, 31, 1131-1140.

161. Palm, A.K.; Novotny, M.V. Analytical characterization of a facile porous polymer monolithic trypsin microreactor enabling peptide mass mapping using mass spectrometry. Rapid Commun. Mass Spectrom. 2004, 18, 1374-1382.

162. Peterson, D.S.; Rohr, T.; Svec, F.; Frechet, J.M. High-throughput peptide mass mapping using a microdevice containing trypsin immobilized on a porous polymer monolith coupled to MALDI TOF and ESI TOF mass spectrometers. J. Proteome Res. 2002, 1, 563-568.

163. Jin, L.J.; Ferrance, J.; Sanders, J.C.; Landers, J.P. A microchip-based proteolytic digestion system driven by electroosmotic pumping. Lab Chip 2003, 3, 11-18.

164. Slysz, G.W.; Schriemer, D.C. On-column digestion of proteins in aqueous-organic solvents. Rapid Commun. Mass Spectrom. 2003, 17, 1044-1050.

165. Strader, M.B.; Tabb, D.L.; Hervey, W.J.; Pan, C.; Hurst, G.B. Efficient and specific trypsin digestion of microgram to nanogram quantities of proteins in organic-aqueous solvent systems. Anal. Chem. 2006, 78, 125-134.

166. Rice, R.H.; Means, G.E.; Brown, W.D. Stabilization of bovine trypsin by reductive methylation. Biochim. Biophys. Acta 1977, 492, 316-321.

167. Hustoft, H.K.; Malerod, H.; Wilson, S.R.; Reubsaet, L.; Lundanes, E.; Greibrokk, T. A critical review of trypsin digestion for LC-MS based proteomics. In Integrative Proteomics; Leung, H.-C.E., Ed.; InTech: Rijeka, Croatia, 2012.

168. Wang, J.; Zhou, C.; Zhang, W.; Yao, J.; Lu, H.; Dong, Q.; Zhou, H.; Qin, L. An integrative strategy for quantitative analysis of the N-glycoproteome in complex biological samples. Proteome Sci. 2014, $12,4$.

169. Harvey, D.J. Derivatization of carbohydrates for analysis by chromatography; electrophoresis and mass spectrometry. J. Chromatogr. B 2011, 879, 1196-1225. 
170. Hase, S.; Ikenaka, T.; Matsushima, Y. Structure analyses of oligosaccharides by tagging of the reducing end sugars with a fluorescent compound. Biochem. Biophys. Res. Commun. 1978, 85, 257-263.

171. Hase, S.; Hara, S.; Matsushima, Y. Tagging of sugars with a fluorescent compound, 2-aminopyridine. J. Biochem. 1979, 85, 217-220.

172. Ritamo, I.; Rabina, J.; Natunen, S.; Valmu, L. Nanoscale reversed-phase liquid chromatographymass spectrometry of permethylated N-glycans. Anal. Bioanal. Chem. 2013, 405, 2469-2480.

173. Suzuki, S. Recent developments in liquid chromatography and capillary electrophoresis for the analysis of glycoprotein glycans. Anal. Sci. 2013, 29, 1117-1128.

174. Higel, F.; Demelbauer, U.; Seidl, A.; Friess, W.; Sorgel, F. Reversed-phase liquidchromatographic mass spectrometric N-glycan analysis of biopharmaceuticals. Anal. Bioanal. Chem. 2013, 405, 2481-2493.

175. Gennaro, L.A.; Harvey, D.J.; Vouros, P. Reversed-phase ion-pairing liquid chromatography/ion trap mass spectrometry for the analysis of negatively charged, derivatized glycans. Rapid Commun. Mass Spectrom. 2003, 17, 1528-1534.

176. Guile, G.; Rudd, P.; Wing, D.; Dwek, R. HPLC Strategies for Profiling and Sequencing Oligosaccharides. In A Laboratory Guide to Glycoconjugate Analysis; Jackson, P., Gallagher, J., Eds.; Birkhäuser: Basel, Switzerland, 1995; pp. 199-234.

177. Mechref, Y.; Novotny, M.V. Miniaturized separation techniques in glycomic investigations. J. Chromatogr. B 2006, 841, 65-78.

178. Buszewski, B.; Noga, S. Hydrophilic interaction liquid chromatography (HILIC)—A powerful separation technique. Anal. Bioanal. Chem. 2012, 402, 231-247.

179. Dong, X.; Wu, R.; Dong, J.; Wu, M.; Zhu, Y.; Zou, H. Recent progress of polar stationary phases in CEC and capillary liquid chromatography. Electrophoresis 2009, 30, 141-154.

180. Jandera, P. Stationary and mobile phases in hydrophilic interaction chromatography: A review. Anal. Chim. Acta 2011, 692, 1-25.

181. Schlichtherle-Cerny, H.; Affolter, M.; Cerny, C. Hydrophilic interaction liquid chromatography coupled to electrospray mass spectrometry of small polar compounds in food analysis. Anal. Chem. 2003, 75, 2349-2354.

182. Nguyen, H.P.; Yang, S.H.; Wigginton, J.G.; Simpkins, J.W.; Schug, K.A. Retention behavior of estrogen metabolites on hydrophilic interaction chromatography stationary phases. J. Sep. Sci. 2010, 33, 793-802.

183. Quiming, N.S.; Denola, N.L.; Soliev, A.B.; Saito, Y.; Jinno, K. Retention behavior of ginsenosides on a poly(vinyl alcohol)-bonded stationary phase in hydrophilic interaction chromatography. Anal. Bioanal. Chem. 2007, 389, 1477-1488.

184. Wang, F.; Khaledi, M.G. Chiral separations by nonaqueous capillary electrophoresis. Anal. Chem. 1996, 68, 3460-3467.

185. Kullolli, M.; Hancock, W.S.; Hincapie, M. Preparation of a high-performance multi-lectin affinity chromatography (HP-M-LAC) adsorbent for the analysis of human plasma glycoproteins. J. Sep. Sci. 2008, 31, 2733-2739. 
186. Hongsachart, P.; Huang-Liu, R.; Sinchaikul, S.; Pan, F.-M.; Phutrakul, S.; Chuang, Y.-M.; Yu, C.-J.; Chen, S.-T. Glycoproteomic analysis of WGA-bound glycoprotein biomarkers in sera from patients with lung adenocarcinoma. Electrophoresis 2009, 30, 1206-1220.

187. Cummings, R.D.; Kornfeld, S. Fractionation of asparagine-linked oligosaccharides by serial lectinAgarose affinity chromatography. A rapid, sensitive, and specific technique. J. Biol. Chem. 1982, 257, 11235-11240.

188. Nishikawa, T.; Kajii, S.; Sato, C.; Yasukawa, Z.; Kitajima, K.; Isobe, M. Alpha-C-mannosyltryptophan is not recognized by conventional mannose-binding lectins. Bioorg. Med. Chem. 2004, 12, 2343-2348.

189. Wada, Y.; Tajiri, M.; Yoshida, S. Hydrophilic affinity isolation and MALDI multiple-stage tandem mass spectrometry of glycopeptides for glycoproteomics. Anal. Chem. 2004, 76, 6560-6565.

190. Potter, O.G.; Breadmore, M.C.; Hilder, E.F. Boronate functionalised polymer monoliths for microscale affinity chromatography. Analyst 2006, 131, 1094-1096.

191. Ren, L.; Liu, Z.; Dong, M.; Ye, M.; Zou, H. Synthesis and characterization of a new boronate affinity monolithic capillary for specific capture of cis-diol-containing compounds. J. Chromatogr. A 2009, 1216, 4768-4774.

192. Ren, L.; Liu, Y.; Dong, M.; Liu, Z. Synthesis of hydrophilic boronate affinity monolithic capillary for specific capture of glycoproteins by capillary liquid chromatography. J. Chromatogr. A 2009, $1216,8421-8425$.

193. Li, H.; Liu, Z. Recent advances in monolithic column-based boronate-affinity chromatography. Trends Anal. Chem. 2012, 37, 148-161.

194. Otsuka, H.; Uchimura, E.; Koshino, H.; Okano, T.; Kataoka, K. Anomalous binding profile of phenylboronic acid with $\mathrm{N}$-acetylneuraminic acid (Neu5Ac) in aqueous solution with varying $\mathrm{pH}$. J. Am. Chem. Soc. 2003, 125, 3493-3502.

195. Ren, L.; Liu, Z.; Liu, Y.; Dou, P.; Chen, H.Y. Ring-opening polymerization with synergistic co-monomers: access to a boronate-functionalized polymeric monolith for the specific capture of cis-diol-containing biomolecules under neutral conditions. Angew. Chem. Int. Ed. Engl. 2009, 48, 6704-6707.

196. Wei, Q.; James, S.L. A metal-organic gel used as a template for a porous organic polymer. Chem. Commun. 2005, 1555-1556.

197. Kolb, H.C.; Finn, M.G.; Sharpless, K.B. Click chemistry: Diverse chemical function from a few good reactions. Angew. Chem. Int. Ed. 2001, 40, 2004-2021.

198. Ellington, A.D.; Szostak, J.W. In vitro selection of RNA molecules that bind specific ligands. Nature 1990, 346, 818-822.

199. Motoyama, A.; Yates, J.R. Multidimensional LC separations in shotgun proteomics. Anal. Chem. 2008, 80, 7187-7193.

200. Wagner, K.; Miliotis, T.; Marko-Varga, G.; Bischoff, R.; Unger, K.K. An automated on-line multidimensional HPLC system for protein and peptide mapping with integrated sample preparation. Anal. Chem. 2002, 74, 809-820.

201. Di Palma, S.; Stange, D.; van de Wetering, M.; Clevers, H.; Heck, A.J.R.; Mohammed, S. Highly sensitive proteome analysis of FACS-sorted adult colon stem cells. J. Proteome Res. 2011, 10, 3814-3819. 
202. Jacobs, J.M.; Diamond, D.L.; Chan, E.Y.; Gritsenko, M.A.; Qian, W.; Stastna, M.; Baas, T.; Camp, D.G., 2nd; Carithers, R.L., Jr.; Smith, R.D.; et al. Proteome analysis of liver cells expressing a fulllength hepatitis $\mathrm{C}$ virus (HCV) replicon and biopsy specimens of posttransplantation liver from HCV-infected patients. J. Virol. 2005, 79, 7558-7569.

203. Fujii, K.; Nakano, T.; Kawamura, T.; Usui, F.; Bando, Y.; Wang, R.; Nishimura, T. Multidimensional protein profiling technology and its application to human plasma proteome. J. Proteome Res. 2004, 3, 712-718.

204. Marcus, K.; Schafer, H.; Klaus, S.; Bunse, C.; Swart, R.; Meyer, H.E. A new fast method for nanoLC-MALDI-TOF/TOF-MS analysis using monolithic columns for peptide preconcentration and separation in proteomic studies. J. Proteome Res. 2007, 6, 636-643.

205. Shiyan, S.D.; Bovin, N.V. Carbohydrate composition and immunomodulatory activity of different glycoforms of alpha1-acid glycoprotein. Glycoconjug. J. 1997, 14, 631-638.

(C) 2015 by the authors; licensee MDPI, Basel, Switzerland. This article is an open access article distributed under the terms and conditions of the Creative Commons Attribution license (http://creativecommons.org/licenses/by/4.0/). 